\title{
IN-PLANE BEHAVIOUR OF EARTHEN MATERIALS: A NUMERICAL COMPARISON BETWEEN ADOBE MASONRY, RAMMED EARTH AND COB
}

\author{
Lorenzo Miccoli ${ }^{1}$, Rui A. Silva ${ }^{2}$, Angelo Garofano ${ }^{3}$ and Daniel V. Oliveira ${ }^{2}$ \\ ${ }^{1}$ Bundesanstalt für Materialforschung und -prüfung (BAM) \\ Division Building Materials \\ Unter den Eichen 87, 12205 Berlin, Germany \\ e-mail: lorenzo.miccoli@bam.de \\ ${ }^{2}$ ISISE University of Minho \\ Department of Civil Engineering \\ Campus de Azurém, 4800-058 Guimarães, Portugal \\ e-mail: \{ruisilva, danvco\}@civil.uminho.pt \\ ${ }^{3}$ DIANA FEA bv \\ Department of Engineering \\ Delftechpark 19a, 2628XJ Delft, The Netherlands \\ e-mail: a.garofano@dianafea.com
}

Keywords: Earthen Materials, Compression Behaviour, Shear Behaviour, Digital Image Correlation, Finite Element Method

\begin{abstract}
The paper presents a comparison between different numerical modelling approaches aiming to simulate the in-plain behaviour of three types of earthen materials, namely adobe masonry, rammed earth and cob. For this purpose, uniaxial and diagonal compression tests were carried out, which allowed determining important mechanical parameters, such as compressive strength, Young's modulus, Poisson's ratio, shear strength and shear modulus. Furthermore, the tests allowed assessing the level of non-linear behaviour of the respective stress-strain relationships as well as the failure modes. The experimental results were then used for the calibration of numerical models (based on the finite element method) for simulating the non-linear behaviour of the earth materials under in-plane shear loading. Both macro- and micro-modelling approaches were considered for this purpose. The procedures adopted for model calibration established the reliability of various modelling strategies for the different loading conditions. The simplified approach based on macromodelling shows a satisfactory accuracy and low computational costs. The results reproducing the uniaxial compression are in good correspondence with the post-elastic behaviour observed in the experimental campaign. The micro-modelling approach adopted to reproduce the shear behaviour, even with higher computational cost, represents a suitable tool to predict the adobe masonry and rammed earth collapse mechanisms.
\end{abstract}




\section{INTRODUCTION}

Earthen materials show interesting environmental advantages when used as building materials [1, [2]. There are several available techniques where these materials are employed with structural purposes, namely as earth blocks (adobe), compressed earth blocks (CEB), rammed earth and cob [3].

Adobe masonry is built with earth block units laid with mortar, usually an earth mortar. The manufacture of adobe masonry usually follows the same principles as those used for fired clay brick masonry. These blocks are produced by throwing a handful of a malleable mass of earth into a mould, and then are demoulded and put to dry under the sun.

Rammed earth is an earthen construction technique in which moistened earth is compacted in consecutive layers within a wooden formwork. Rammed earth exhibits two distinctive physical characteristics: a low moisture content, usually below the plastic limit of earth ('soilmoist') when filled into the formwork and a wide, poorly sorted particle size distribution ranging from clay to gravel-size (up to $64 \mathrm{~mm}$ ) fractions.

Cob is a mixture of earth and plant fibres, where walls made of cob can be regarded as fibre-reinforced monolithic structural elements. The largest particle size of the soil usually does not exceed the sand fraction. The earth is mixed with water to a plastic consistency and then the straw fibres are worked upon to shape the walls, layer by layer $[4,5]$.

In last decade several studies were carried out to numerically model the behaviour of earthen materials under static $[7,8,9,11,12,13,14,15,16,17]$ and under pseudo-dynamic loading $[18,19,20]$. This article presents a comparative study on the numerical modelling of three different earthen materials under static in-plane loading.

The material characterization and its modelling are hardly predictable due the variability shown by the raw earthen materials. For this reason, a detailed characterisation of the earthen materials properties is required when the use of complex constitutive laws is necessary. In addition, considering the aforementioned aspects, the constitutive model, selected referring to the material behaviour and the analysis computational demand, needs to provide a good match between representativeness, complexity, accuracy and reliability.

The first part of the paper presents the mechanical characterisation of earthen materials carried out. Earthen wallets were tested in the BAM laboratories within an experimental program whose goal was to derive the basic mechanical properties to employ in the numerical simulation. The second part of the paper deals with the numerical modelling of the earthen wallets implemented in FEM software TNO DIANA 9.6 [21].

The aim of the numerical analysis is to simulate the non-linear shear behaviour of earthen materials. For adobe masonry the non-linear constitutive laws are based on the multidirectional fixed crack model and combined interface model. A total strain rotating crack model (TSRCM) was used for rammed earth and cob. The macro-modelling approach was considered for the simulation of the experimental tests, and the respective FEM models were calibrated according to the experimental results obtained. Additionally, the micro-modelling approach intended to evaluate the influence of the interfaces between layers on the shear behaviour of rammed earth and failure mechanism block-mortar in adobe masonry. 


\section{EXPERIMENTAL PROGRAM}

\subsection{Materials and preparation of the samples}

In the experimental program the earthen wallets were tested under uniaxial compression and diagonal compression. Earthen materials for the experiments were sourced from a local manufacturer of prefabricated earthen building products. Earth blocks were produced by a mechanised moulding procedure (no compression) with a size of $240 \mathrm{~mm} \times 115 \mathrm{~mm} \times$ $71.5 \mathrm{~mm}$. Earth mortar was provided as pre-mixed dry mortar and was mixed with water for sample preparation according to DIN 18946 [22]. Adobe masonry wallets of size $500 \mathrm{~mm} \times$ $500 \mathrm{~mm} \times 115 \mathrm{~mm}$ with a bulk density $(\gamma)$ of $1870 \mathrm{~kg} / \mathrm{m}^{3}$ were produced by laying six earthen unit courses in accordance with EN 1052-1 [23]. Samples were built without pre-wetting the earth blocks for compression tests. For the shear tests, samples with wetted blocks were built.

The rammed earth wallets were manufactured with approximate dimensions of $500 \mathrm{~mm} \times$ $500 \mathrm{~mm} \times 110 \mathrm{~mm}$. The manufacturing process consisted in manually compacting fairly dry earth (moisture content $9-10 \%$ ) in six layers within a plywood formwork, with a timber rammer. The resulting average layer thickness after compaction was of about $84 \mathrm{~mm}$. The wallets showed a $\gamma$ of $2190 \mathrm{~kg} / \mathrm{m}^{3}$. For the basic cob formulation, the premixed earth was first mixed with water to plastic consistency. Afterwards the straw fibres were added and mixed thoroughly in a high performance shear mixer. The cob mass was then thrown onto the cob heap in a diagonal pattern. By throwing the plastic cob, mass void space and air inclusions are minimized. Wallets of $420 \mathrm{~mm} \times 420 \mathrm{~mm} \times 115 \mathrm{~mm}$ were cut from a large cob heap showing a $\gamma$ of $1430 \mathrm{~kg} / \mathrm{m}^{3}$. After production, the wallets were stored in a climate room at $23{ }^{\circ} \mathrm{C}$ and $50 \%$ relative humidity $(\mathrm{RH})$ for drying. Samples were removed from the climate room shortly before mechanical testing took place. The detailed description of material characterisation is reported elsewhere $[5,6]$.

\subsection{Uniaxial compression tests}

A layer of low strength cement mortar was used between the top and bottom surfaces of samples and the supports to regularise the contact surfaces. The distribution of the load applied to the samples was given by means of two I-shaped steel profiles fixed at the top and bottom surfaces. The compression tests were performed under displacement control. The test speed was set at constant value to reach the failure within 20-30 min. The deformations of the samples were measured through linear variable differential transformers (LVDTs).

For adobe masonry, the compressive strength $\left(f_{c}\right)$ values ranged between 2.7 and $3.8 \mathrm{~N} / \mathrm{mm}^{2}$. The Young's modulus $(E)$ was in the range of $587-1071 \mathrm{~N} / \mathrm{mm}^{2}$. Failure was usually abrupt after maximum stress was reached, it was visible by vertical or diagonal cracks with sometimes cone shaped cracking pattern, at least one side, sometimes on both sides. Crack patterns of the wallets are shown in Fig. 1a. Accordingly the stress-strain curves (Fig. 1b) exhibit a short phase of post-peak strain softening under compression, due to its brittle behaviour under uniaxial load. Fig. 2a depicts the crack pattern at the failure of one of the rammed earth wallets. The crack pattern was characterized by the formation of a cone shape at the top, bottom or at both regions. The wallets exhibited a brittle failure in a short time after achieving their maximum compressive stress. The axial stress-strain curves obtained from the compression tests are presented in Fig. 2b, as well as the respective envelope. These curves thoroughly highlight the non-linear behaviour of rammed under uniaxial compression, which starts from low stress levels. It should be noted that $f_{c}$ showed relatively low scattering and varied between 3.3 and $3.9 \mathrm{~N} / \mathrm{mm}^{2}$, while $E$ presented relatively high scattering and varied between 2844 and $5048 \mathrm{~N} / \mathrm{mm}^{2}$. 


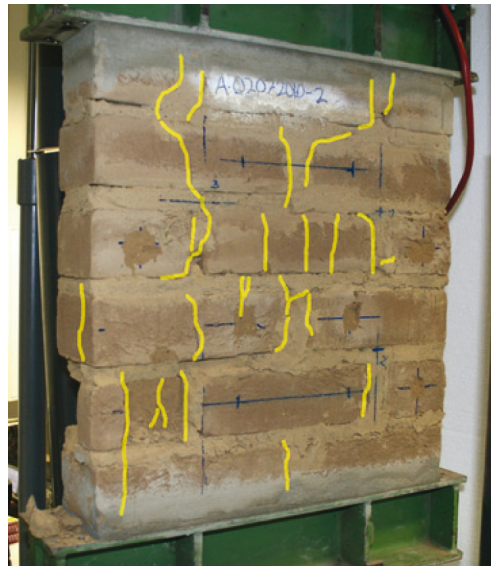

(a)

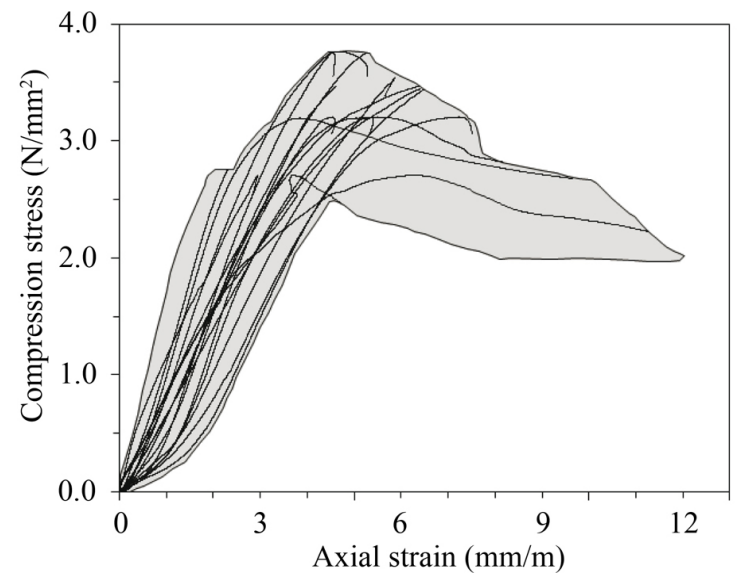

(b)

Figure 1: Compression tests on adobe masonry: (a) crack pattern of a wallet; (b) compression stress-axial strain curves and respective envelope.

A typical crack pattern at the failure of one of the cob wallets tested is shown in Fig. $3 \mathrm{a}$. Fig. $3 \mathrm{~b}$ reports the compression tests results in terms of axial stress-strain curves and the respective envelope. These curves draw attention to the non-linear behaviour of cob under compression. The values of $f_{c}$ showed relatively low scattering and varied in the range of 1.55 $1.63 \mathrm{~N} / \mathrm{mm}^{2}$. Also $E$ presented relatively low scattering and varied in the range of 977$1084 \mathrm{~N} / \mathrm{mm}^{2}$.

The deformations of the samples were relatively high, where the maximum values measured for axial strain $(\varepsilon)$ were higher than $30 \mathrm{~mm} / \mathrm{m}$. Due to the presence of straw, the cob samples showed a ductile behaviour under compressive load, without distinctive maximum in a long post-peak phase. Crack patterns after the tests were almost random and only in one sample a cone shaped failure was observed.

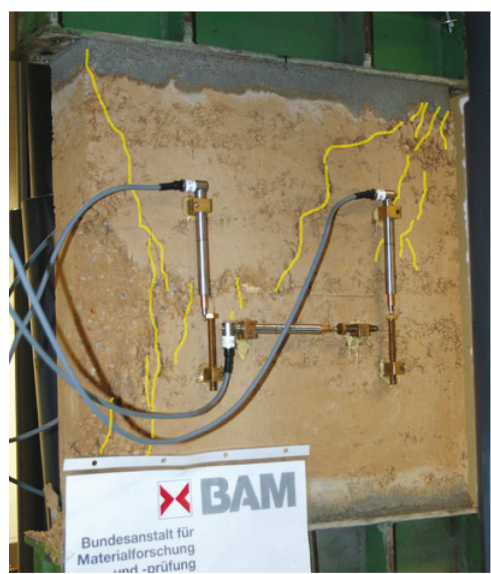

(a)

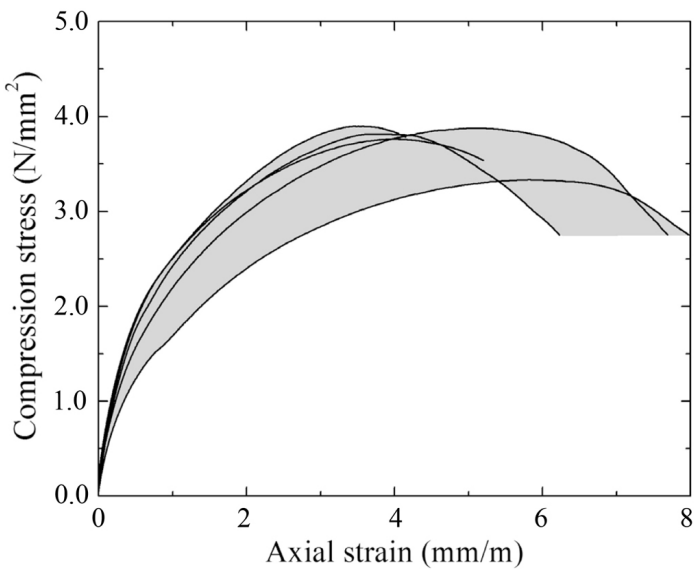

(b)

Figure 2: Compression tests on rammed earth: (a) crack pattern of a wallet; (b) compression stress-axial strain curves and respective envelope. 


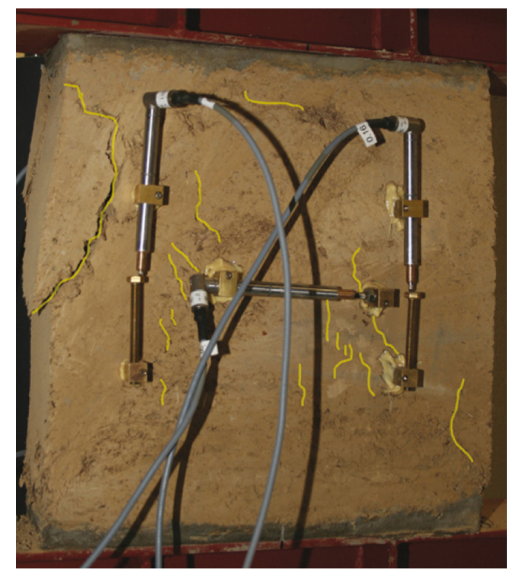

(a)

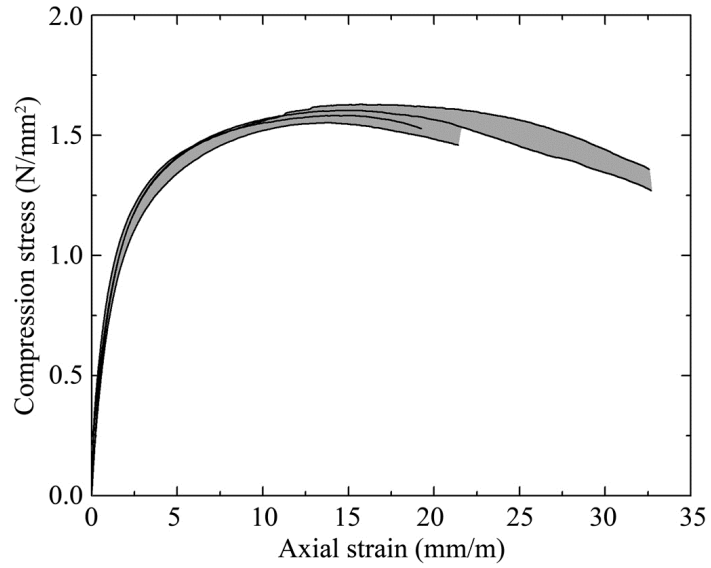

(b)

Figure 3: Compression tests on cob: (a) crack pattern of a wallet; (b) compression stress-axial strain curves and respective envelope.

Pull-off tests were performed to obtain an estimation of the tensile strength $\left(f_{t}\right)$ for adobe masonry and cob. In the case of cob, the strength obtained from these tests is expected to be higher than the real tensile strength, due to some limitations of the test, such as resin impregnation and lack of control regarding the failure mechanism. The average value obtained corresponds to about $20 \%$ of $f_{c}$, which is a relatively high relation when compared with the $10 \%$ relation generally assumed in the modelling of masonry materials. Table 1 summarises the mechanical properties obtained from compression and pull-off tests.

\begin{tabular}{lllll}
\hline Material & $f_{c}\left(\mathrm{~N} / \mathrm{mm}^{2}\right)$ & $E\left(\mathrm{~N} / \mathrm{mm}^{2}\right)$ & $v(-)$ & $f_{t}\left(\mathrm{~N} / \mathrm{mm}^{2}\right)$ \\
\hline Adobe masonry & $3.28(0.40)$ & $803^{\mathrm{b}}(204)$ & $0.37(0.13)$ & $0.52^{\mathrm{c}}(0.12) / 0.30^{\mathrm{d}}(0.08)$ \\
Rammed earth & $3.73(0.23)$ & $4207^{\mathrm{a}}(921)$ & $0.27(0.03)$ & $\mathrm{nd}$ \\
Cob & $1.59(0.03)$ & $1021^{\mathrm{a}}(50)$ & $0.14(0.06)$ & $0.32(0.06)$ \\
\hline
\end{tabular}

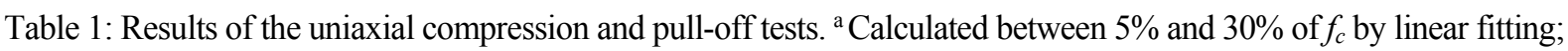

${ }^{\mathrm{b}}$ determined at $1 / 3$ of maximum stress; ${ }^{\mathrm{c}}$ adobe; ${ }^{\mathrm{d}}$ mortar; standard deviations in brackets; nd = not determined.

\subsection{Diagonal compression tests}

Diagonal compression tests were performed according to the standard ASTM E 519-10 [24]. The LVDTs were fixed at both sides of the samples. A layer of low strength cement mortar was used between the bases of samples and the supports to regularise the contact surfaces. Diagonal compression tests on adobe masonry were carried out under displacement control. According to the standard test method, the loading speed was adjusted in a way that the failure point was reached after 1-2 minutes. The experimental results evidenced how the global performance of adobe masonry elements is mainly governed. The sample yields the stress until a first diagonal crack appears by exceeding the maximum elastic horizontal strain. The crack ran not only along joints but also through blocks (Fig. 4a). At the second yielding point the sample failed by sliding of the blocks along the joints until complete collapse. The stress-strain curve of most of samples showed a distinctive yielding point, when the elastic limit of the samples was reached and first cracks appeared (Fig. 4b). This type of stress-strain response is linked to the actual failure mode of the sample. Details on mechanical testing are reported in a previous study $[9,10]$. The shear strength $\left(f_{s}\right)$ of the samples was calculated from the maximum load. The $f_{s}$ values ranged between 0.15 and $0.30 \mathrm{~N} / \mathrm{mm}^{2}$. The initial shear strength $\left(f_{v o}\right)$ of the earth mortar and its bond behaviour to the earth block is a crucial factor. Therefore, shear tests according to EN 1052-3 [25], procedure A, were carried out. 


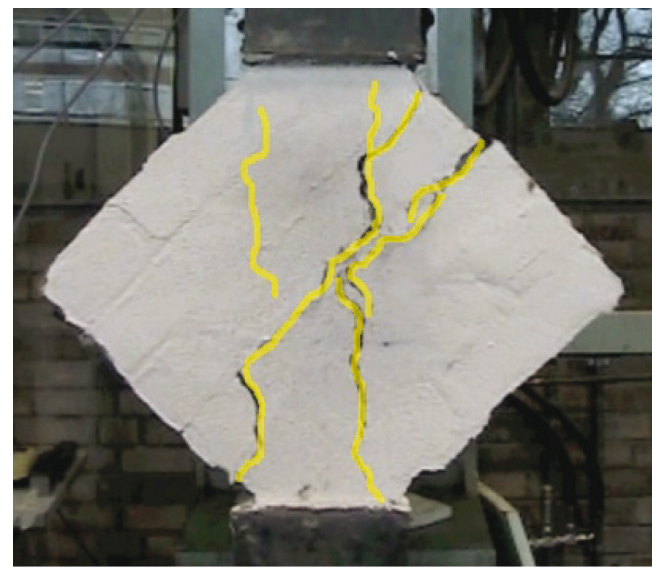

(a)

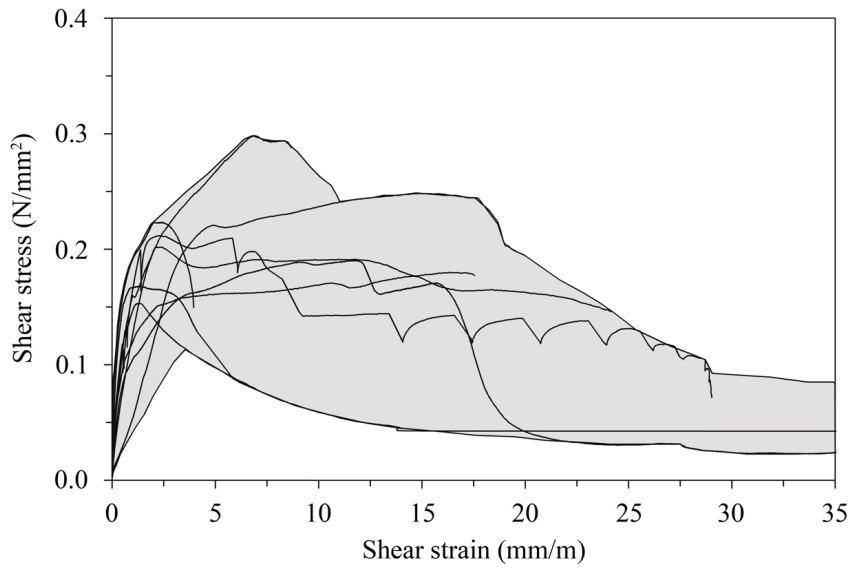

(b)

Figure 4: Diagonal compression tests on adobe masonry: (a) crack pattern of a wallet; (b) shear stress-shear strain curves and respective envelope.

For rammed earth and cob the tests were performed under force control at a rate of about $130 \mathrm{~N} / \mathrm{s}$. The failure of the rammed earth samples was typically preceded by the appearance of a crack close to the early peak shear stress. Then, further cracks developed forming a system of running cracks that crossed diagonally the sample from the top to the bottom support (Fig. 5a). Cracking at the interface between the layers was also observed, where the diagonal systems of cracks tended to follow partially this interface.

Fig. 5b presents the shear stress-shear strain curves, as well as the respective envelope. In general, the wallets exhibited an early peak shear stress, which was followed by shear hardening. The shear hardening phase imparts most of the shear deformations occurring in the tested samples. Both $f_{s}$ and shear modulus $(G)$ showed relatively high scattering, where $f_{s}$ varied between 0.54 and $0.83 \mathrm{~N} / \mathrm{mm}^{2}$ and $G$ varied between 1260 and $2146 \mathrm{~N} / \mathrm{mm}^{2}$. Details on mechanical testing are reported in a previous study [8].

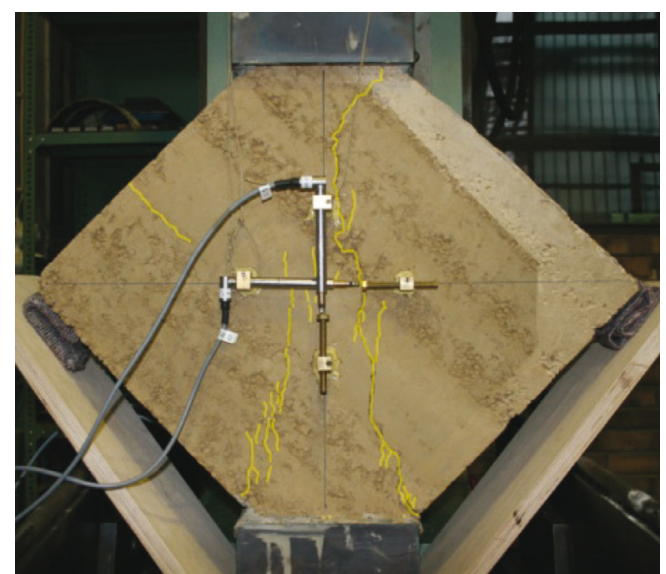

(a)

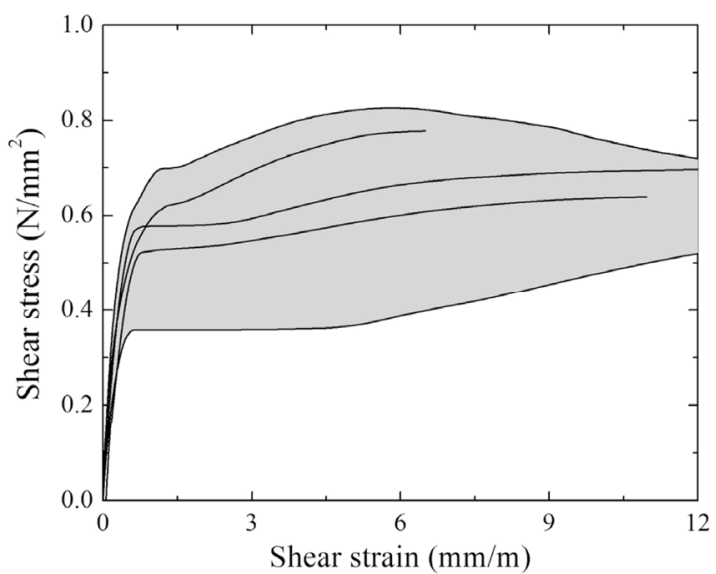

(b)

Figure 5: Diagonal compression tests on rammed earth: (a) crack pattern of a wallet; (b) shear stress-shear strain curves and respective envelope.

The cob samples failure occurred with the initiation of a main crack at the middle of the samples, which progressed towards the supports in diagonal direction. Cracking initiation was observed to occur near the maximum load. The typical failure mode of the wallets is illustrated in Fig. 6a showing the cracking pattern at failure. 
Fig. $6 \mathrm{~b}$ presents the shear stress-shear strain curves, along with the respective envelope. In opposition to the compressive behaviour of cob, the shear behaviour presents very high scattering. The wallets exhibited a noticeable non-linear behaviour in shear, with a very large hardening phase. This phase is probably depending from the contribution of the fibres to the shear behaviour, allowing the wallets to achieve large shear strains $\gamma_{s}$ (higher than $8 \mathrm{~mm} / \mathrm{m}$ ) before failure. All parameters showed relatively high scattering, where $f_{s}$ varied in the range of $0.37-0.64 \mathrm{~N} / \mathrm{mm}^{2}$, shear strain at the maximum shear stress $\left(\gamma_{s}\right)$ varied in the range of 5.6$10.7 \mathrm{~mm} / \mathrm{m}$ and $G$ in the range $311-634 \mathrm{~N} / \mathrm{mm}^{2}$. Details on mechanical testing are reported in a previous study [26]. The results of the diagonal compression tests are listed in Table 2.

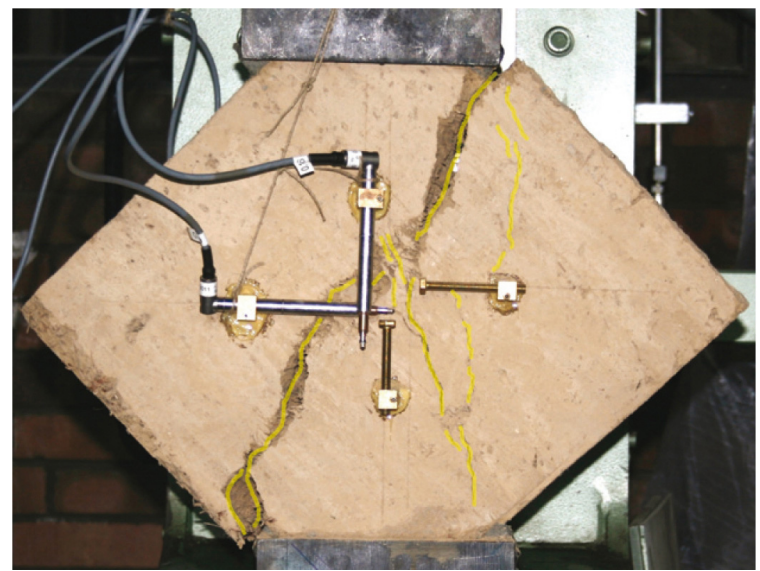

(a)

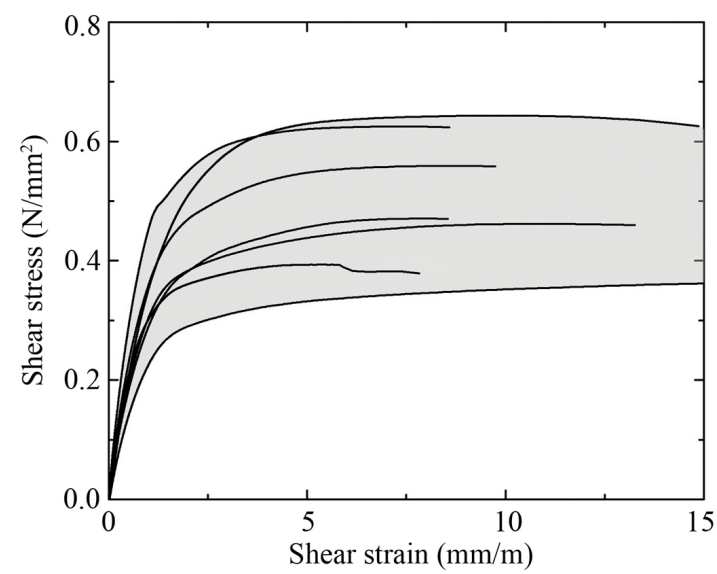

(b)

Figure 6: Diagonal compression tests on cob: (a) crack pattern of a wallet; (b) shear stress-shear strain curves and respective envelope.

\begin{tabular}{llll}
\hline Material & $f_{s}\left(\mathrm{~N} / \mathrm{mm}^{2}\right)$ & $G\left(\mathrm{~N} / \mathrm{mm}^{2}\right)$ & $f_{\text {vo }}\left(\mathrm{N} / \mathrm{mm}^{2}\right)$ \\
\hline Adobe masonry & $0.21(0.05)$ & $397^{\mathrm{b}}(340)$ & 0.018 \\
Rammed earth & $0.70(0.11)$ & $1582^{\mathrm{a}}(333)$ & - \\
Cob & $0.50(0.11)$ & $442^{\mathrm{a}}(100)$ & - \\
\hline
\end{tabular}

Table 2: Results of the diagonal compression tests. ${ }^{\mathrm{a}}$ Calculated between $5 \%$ and $30 \%$ of $f_{s}$ by linear fitting; ${ }^{\mathrm{b}}$ determined at $1 / 3$ of maximum stress, standard deviations in brackets.

\section{NUMERICAL MODELLING}

\subsection{Geometry, boundary conditions and loading}

The finite element method (FEM) was used to numerically simulate the mechanical behaviour of the wallets tested under uniaxial and diagonal compression tests. The models were prepared and implemented by means of the FEM software TNO DIANA 9.6 [21].

A plane stress state was assumed for all models, allowing analysis with lower complexity and computer processing demand. The $2 \mathrm{D}$ analysis represents a valid assumption given the geometry of the wallets and the in-plane loading applied. Eight-noded quadrilateral elements (CQ16M) were used to simulate the three earthen materials in both macro- and micromodelling approaches. In the micro-modelling approach, interfaces between layers were simulated using six-noded zero-thickness interface elements (CL12I). The load was applied by imposing uniformly distributed vertical displacements on the constrained nodes at the top 
of the FEM models. As the self-weight was expected to have marginal contribution to the stress state, it was not considered in the modelling.

In the simulation of the compression tests of adobe masonry, the two constraining rigid steel beams were also included in the model, by means of two additional surfaces at the base and on top of the wallet, each with a height of $120 \mathrm{~mm}$. The wallets tested under diagonal compression were modelled similarly to the uniaxial compression test previously described. The diagonal load was applied through the steel shoes, included in the model, and placed at two opposite corners of the wallet to correctly distribute the load over the wallet. The width of the steel supports over the two sides of the corner was $149 \mathrm{~mm}$. modelled with six-noded triangular elements (CT12M). The boundary conditions were defined by considering a width of the supports of about $125 \mathrm{~mm}$.

Both macro- and micro-modelling approaches were considered. In the first case adobe masonry was considered as a homogeneous and continuous material, whereas in the second case the inhomogeneity of masonry was taken into account through the definition of a discontinuous system of units connected by interfaces at the centre of the mortar joints. The macromodel is a suitable tool for practical application in large structures and was based on plasticity formulations for isotropic quasi-brittle materials with consideration of the cracking behaviour. For the micro-model, the approach undertaken was based on the definition of appropriate elements whose behaviour was governed by a composite interface material model. The composite interface model allows capturing all possible masonry failure mechanisms, such as tensile cracking, frictional slip and crushing along the interfaces.

Rammed earth was firstly treated as a homogeneous continuum medium, which allows obtaining models with lower complexity than those obtained from a micro-modelling approach. Then, the rammed earth was treated as a set of stacked layers of finite elements to simulate the interfaces between compaction layers. Cob was modelled only as a homogenous and continuous material using macro-modelling. Then, the mechanical parameters were calibrated through the comparison of the numerical outcomes with the experimental results presented in the previous section. Characteristics of numerical models are reported in Table 3.

\begin{tabular}{|c|c|c|c|c|c|}
\hline Material & \multicolumn{2}{|c|}{ Adobe masonry } & \multicolumn{2}{|c|}{ Rammed earth } & Cob \\
\hline Modelling & Macro & Micro & Macro & Micro & Macro \\
\hline Dimension $(\mathrm{mm})$ & $500 \times 500>$ & 115 & $499 \times 50$ & $\times 117$ & $401 \times 407 \times 123$ \\
\hline Mesh elements & CQ16M & $\begin{array}{l}\text { CQ16M } \\
\text { CT12M }\end{array}$ & CQ16M & $\begin{array}{l}\text { CQ16M } \\
\text { CT12M }\end{array}$ & CQ16M - \\
\hline No. of elements & $484^{\mathrm{a}} / 576^{\mathrm{b}}$ & 1140 & 400 & $560^{\mathrm{a}} / 580^{\mathrm{b}}$ & 400 \\
\hline
\end{tabular}

Table 3: Numerical modelling approach and geometry; ${ }^{\mathrm{a}}$ uniaxial compression; ${ }^{\mathrm{b}}$ diagonal compression.

\subsection{Adobe masonry}

\subsubsection{Constitutive laws}

A multi-directional fixed crack model was assumed [27] where cracking is specified as a combination of tension cut-off, tension softening and shear retention. A constant tension cutoff according to Rankine criterion was used, combined with a yielding criterion for compression according to Von Mises criterion (Fig. 7a). The shear retention was assumed to be constant (Fig. 7b). Table 4 reports the values of the mechanical properties considered for the macro-model. In particular, the assumed $E$ and $v$ correspond to the mean values obtained from uniaxial tests. 


\begin{tabular}{|c|c|c|c|c|c|c|}
\hline $\begin{array}{l}E \\
\left(\mathrm{~N} / \mathrm{mm}^{2}\right)\end{array}$ & $\begin{array}{l}v \\
(-)\end{array}$ & $\begin{array}{l}f_{t} \\
\left(\mathrm{~N} / \mathrm{mm}^{2}\right)\end{array}$ & $\begin{array}{l}f_{c} \\
\left(\mathrm{~N} / \mathrm{mm}^{2}\right)\end{array}$ & $\begin{array}{l}\beta \\
(-)\end{array}$ & $\begin{array}{l}\text { Compressive } \\
\text { behaviour }\end{array}$ & $\begin{array}{l}\text { Tensile } \\
\text { behaviour }\end{array}$ \\
\hline 803 & 0.37 & 0.30 & 3.28 & 0.20 & Multi-linear law (Fig. 7d) & Brittle \\
\hline
\end{tabular}

Table 4: Initial values of parameters assumed for adobe masonry macro-model (uniaxial compression).

The $f_{c}$ was assumed as the mean value from the tests as well. As a comparison, the mean compressive strength was calculated also excluding the extreme values obtained from the tested wallets. However, a difference of $0.87 \%$ with respect to the value used in the numerical model was found being not relevant for the outcomes of the analysis. The coefficient of shear retention $(\beta)$ was chosen in the range of $0.15-0.25$ typical of similar brittle or quasi-brittle materials. This parameter allows to describe the post-cracking shear behaviour and was defined in order to provide the sample with a certain value of stiffness after cracking due to interlocking phenomena [27, 28, 29].

The uniaxial constitutive law considered for tension is brittle (Fig. 7c) due to limited information regarding the tensile behaviour of the tested masonry. The $f_{t}=0.3 \mathrm{~N} / \mathrm{mm}^{2}$ was assumed as the tensile strength of the mortar employed for the joints. For compression, a multilinear law (Fig. 7d) was assumed, based on the results of the experimental tests under uniaxial compression in terms of stress-strain diagram, which lead to satisfactory results.

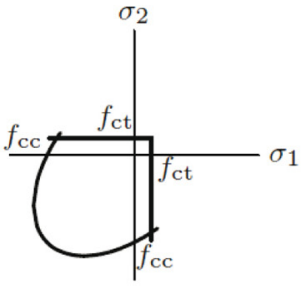

(a)

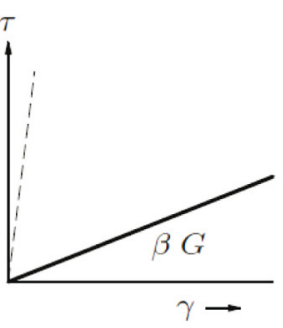

(b)

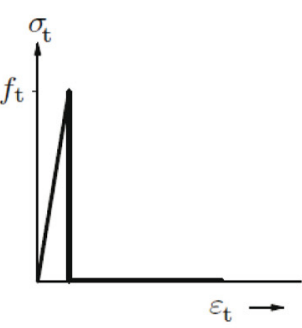

(c)

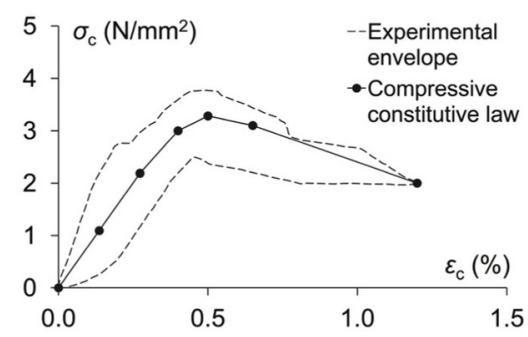

(d)

Figure 7: Material model assumed in the macro-modelling of adobe masonry: (a) Rankine/Von Mises plasticity models; (b) constant shear retention law; (c) brittle tensile behaviour; (d) compressive behaviour [21].

In the micro-modelling approach the model was built considering geometrically expanded units represented by continuous elements, while the behaviour of the mortar joints and unitmortar interface is lumped into discontinuous interface elements. According to this approach, each joint, consisting of a mortar layer and the two unit-mortar interfaces, is lumped into a 'mean' interface while the units are expanded in order to keep the geometry unchanged. Masonry is thus considered as a set of elastic blocks bonded by potential fracture/slip lines at the centre of joints.

The higher level of accuracy of the micro-model in the reproduction of the obtained experimental results lays in the possibility to take into account all the masonry failure mechanisms. In the present case, all the damage was considered to be concentrated in the weak joints and in potential pure tensile cracks in the blocks, vertically placed in the model in the middle of each unit. Therefore, according to the geometry outline reported in Fig. 8a, the wallet was subdivided into expanded block elements connected through joint interfaces. A second type of interface was also included on the half of each block. This method accounted for potential cracks through the units, and resulted to be quite a reliable method from the convergence point of view compared to the use of smeared crack models for the units, thus effective in preventing a wall's response characterised by overstrength [30, 31].

In the micro-model such extended elements, representing the earth block units, were described through a linear-elastic material, while the non-linearities have been concentrated at 
the interfaces. A good approximation of the failure mechanisms for the in-plane loaded masonry wallets can be described by the constitutive model developed by Lourenço and Rots [32], shown in Fig. 8b. This model assumes three failure modes: tension cut-off, compression cap, and shear failure, developed under plasticity concepts. The internal damage associated with each failure mechanism is modelled in the mortar joints using internal parameters related to fracture energy in tension, compression and shear. Such interface material model allows considering possible tensile cracking, crushing or sliding along the joints.

The $E$ and $v$ of the units are taken from the characterisation tests on adobe samples [9]. The $f_{t}$ value of earth blocks obtained from the tests was assumed for the potential block cracks, while for their stiffness and tensile fracture energy $\left(G_{f}^{I}\right)$ values available in the literature [30, 33] were assumed. The micro-modelling approach based on interface finite elements requires the definition of the joint stiffness. In the present case, the values assumed in the numerical models were calculated from the mean value of $E$ obtained from the experimental uniaxial compression tests (Table 1). In the followed approach, the stiffness of the units was kept unmodified, while the normal joint stiffness $\left(K_{n, j o i n t}\right)$ was calculated using the following equation [33]:

$$
K_{n, \text { joint }}=1 /\left(h\left(1 / E_{\text {wall }}-1 / E_{\text {block }}\right)\right)
$$

Whereby the height of the block $(h)$ is equal to $72 \mathrm{~mm}$, and the tangential stiffness $\left(K_{s, j o i n t}\right)$ was calculated directly from the normal stiffness using the theory of elasticity as follows:

$$
K_{s, j o i n t}=K_{n, j o i n t} / 2(1+v) .
$$

Furthermore, in order to describe the possible mechanism of cracking of the units, an additional interface discrete cracking law was included in the model. The law is based on a total deformation theory, which expresses the tractions as a function of the total relative displacements, the crack width, and the crack slip. For tensile softening an exponential law has been assumed (Fig. 8c). The micro-properties assumed for earth blocks and earth mortar are reported in Table 5.

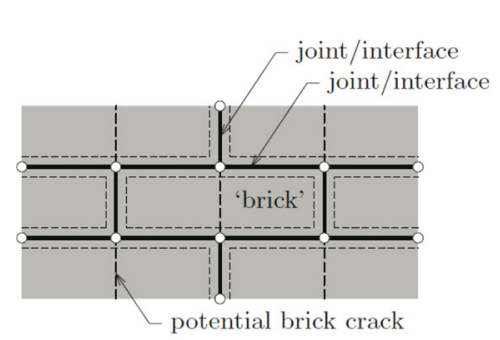

(a)

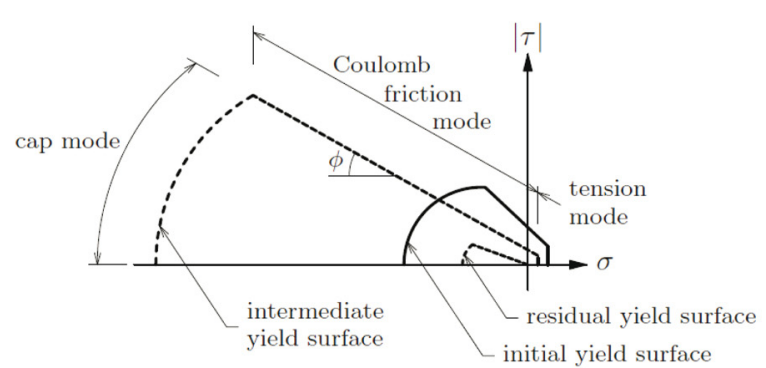

(b)

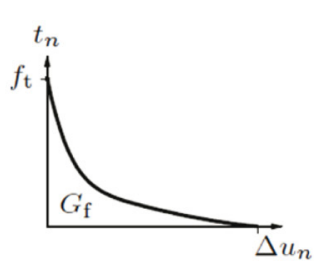

(c)

Figure 8: Discretisation and connectivity adopted in the micro-modelling (a). Combined cracking-shearing-

\begin{tabular}{|c|c|c|c|c|c|c|c|}
\hline Unit & & Joint (stif & ess) & Unit crack & & & \\
\hline $\begin{array}{l}E \\
\left(\mathrm{~N} / \mathrm{mm}^{2}\right)\end{array}$ & $\begin{array}{l}v \\
(-)\end{array}$ & $\begin{array}{l}K_{n \text {.joint }} \\
\left(\mathrm{N} / \mathrm{mm}^{3}\right)\end{array}$ & $\begin{array}{l}K_{s, j o i n t} \\
\left(\mathrm{~N} / \mathrm{mm}^{3}\right)\end{array}$ & $\begin{array}{l}k_{n} \\
\left(\mathrm{~N} / \mathrm{mm}^{3}\right)\end{array}$ & $\begin{array}{l}k_{s} \\
\left(\mathrm{~N} / \mathrm{mm}^{3}\right)\end{array}$ & $\begin{array}{l}f_{t, \text { crack }} \\
\left(\mathrm{N} / \mathrm{mm}^{2}\right)\end{array}$ & $\begin{array}{l}G_{\text {f,crack }}^{I} \\
(\mathrm{~N} / \mathrm{mm})\end{array}$ \\
\hline 2197 & 0.45 & 17.57 & 6.41 & $1.0 \cdot 10^{4}$ & $1.0 \cdot 10^{3}$ & 0.52 & 0.08 \\
\hline
\end{tabular}
crushing model for joint interfaces (b) and discrete cracking relationship for tensile half-block cracks (c) [21].

Table 5: Elastic properties for blocks, joints and potential block cracks of adobe masonry. 
The inelastic properties of the joint interfaces are reported in Table 6.

\begin{tabular}{lllllllll}
\hline Tension & \multicolumn{3}{c}{ Shear } & \multicolumn{7}{c}{ Compression } \\
\hline$f_{\text {t,joint }}$ & $G_{f}^{I_{f}}$ & $c$ & $\tan \varphi$ & $\tan \psi$ & $G^{I_{f}}$ & $f_{c, \text { joint }}$ & $C_{s s}$ & $G_{f}^{c_{f}}$ \\
$\left(\mathrm{~N} / \mathrm{mm}^{2}\right)$ & $(\mathrm{N} / \mathrm{mm})$ & $\left(\mathrm{N} / \mathrm{mm}^{2}\right)$ & $(-)$ & $(-)$ & $(\mathrm{N} / \mathrm{mm})$ & $\left(\mathrm{N} / \mathrm{mm}^{2}\right)$ & $(-)$ & $(\mathrm{N} / \mathrm{mm})$ \\
\hline 0.01 & 0.005 & 0.018 & 0.575 & 0 & 0.05 & $3.28-3.0-2.19$ & 16 & 0.6 \\
\hline
\end{tabular}

Table 6: Inelastic properties for the joints of adobe masonry.

\subsubsection{Calibration of the models and results}

As expected, the macro-model, based on the experimental data, is able to provide results in agreement with the experimental tests in terms of uniaxial stress-strain behaviour (Fig. 9). The numerical analysis was also carried out considering a parabolic law for compression. However, the model resulted to be unsatisfactorily able to follow the non-linear behaviour of the tested wallet after the linear branch. In Fig. 10 the cracking pattern of the wallet at different load levels is reported, showing the progression of damage in the homogeneous material. In this case, the model gives a less realistic representation of the cracks in the wallets, which resulted in a symmetric pattern, while in the reality an asymmetric distribution arises.

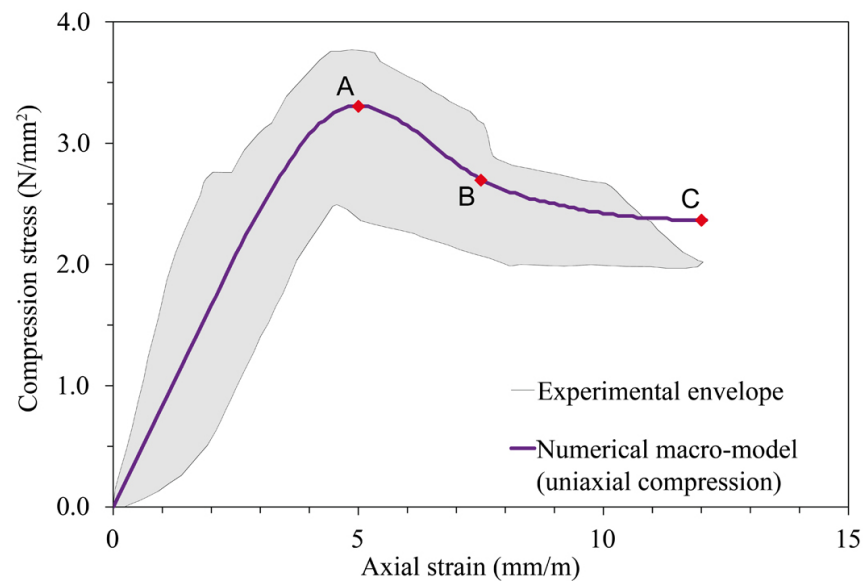

Figure 9: Comparison between experimental and macro-model numerical results under axial compression.

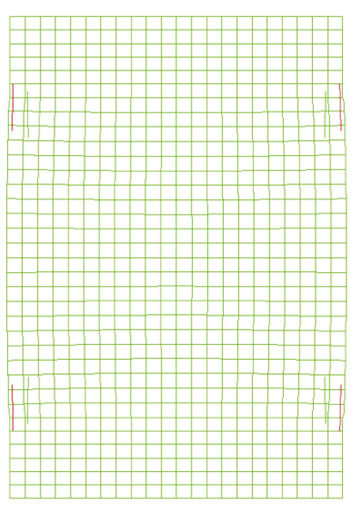

$\sigma=3.30 \mathrm{~N} / \mathrm{mm}^{2}$

(a)
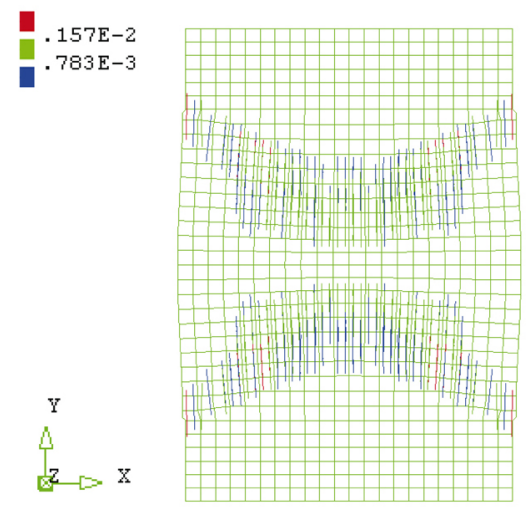

$\sigma=2.70 \mathrm{~N} / \mathrm{mm}^{2}$

(b)
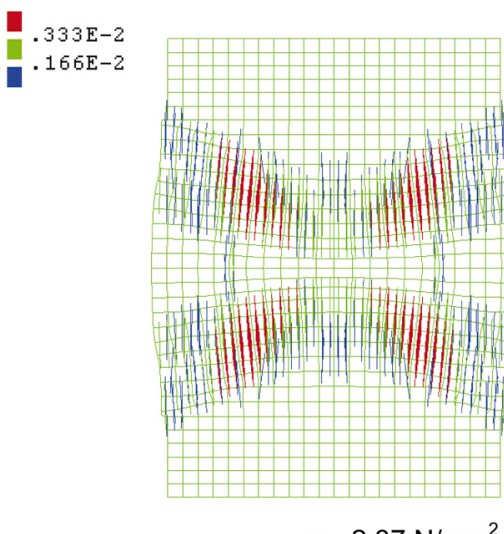

$\sigma=2.37 \mathrm{~N} / \mathrm{mm}^{2}$

(c)

Figure 10: Cracking progression in the adobe masonry macro-model under axial compression at different levels of compressive strain: (a) $\varepsilon=5 \mathrm{~mm} / \mathrm{m}$; (b) $\varepsilon=7.5 \mathrm{~mm} / \mathrm{m}$; (c) $\varepsilon=12 \mathrm{~mm} / \mathrm{m}$. 
In the first phase, a numerical analysis was performed considering the same material model assumed for the uniaxial compression tests, with the aim to reproduce the shear behaviour as well. The results of the analysis showed a shear strength of the masonry higher than the experimental one, assumed to be due to the poor performance of the employed yielding criterion in reproducing the behaviour of a simple element subjected to diagonal compression. Furthermore, an attempt was carried out setting the $f_{t}$ of the masonry to the value of cohesion $(c)$ (initial shear strength $f_{v 0}$ ) obtained from the shear tests on the earth block/mortar joint samples equal to $0.018 \mathrm{~N} / \mathrm{mm}^{2}$. The only sensitive difference observed from the model was in the initial stiffness of the curve. Therefore, a Mohr-Coulomb criterion was included in the material model to simulate the behaviour of the sample tested in diagonal compression. The adopted parameters for materials are summarised in Table 7.

\begin{tabular}{|c|c|c|c|c|c|c|c|}
\hline $\begin{array}{l}E \\
\left(\mathrm{~N} / \mathrm{mm}^{2}\right) \\
\end{array}$ & $\begin{array}{l}v \\
(-)\end{array}$ & $\begin{array}{l}f_{t} \\
\left(\mathrm{~N} / \mathrm{mm}^{2}\right)\end{array}$ & $\begin{array}{l}f_{c} \\
\left(\mathrm{~N} / \mathrm{mm}^{2}\right)\end{array}$ & $\begin{array}{l}\beta \\
(-)\end{array}$ & $\begin{array}{l}c \\
\left(\mathrm{~N} / \mathrm{mm}^{2}\right)\end{array}$ & $\begin{array}{l}\sin \varphi \\
(-)\end{array}$ & $\begin{array}{l}\text { Tensile } \\
\text { behaviour }\end{array}$ \\
\hline 803 & 0.37 & 0.30 & 3.28 & 0.20 & 0.018 & 0.755 & Brittle \\
\hline
\end{tabular}

Table 7: Initial values of parameters assumed for adobe masonry macro-model (diagonal compression).

In particular, the same parameters already employed in the uniaxial compression model were used. The Mohr-Coulomb criterion is based on the definition of the cohesion coefficient and friction angle: such values were assumed equal to the values obtained from the shear tests on the earth block/mortar joint samples. As it can be seen from Fig. 11, a good approximation of the experimental shear behaviour was obtained.

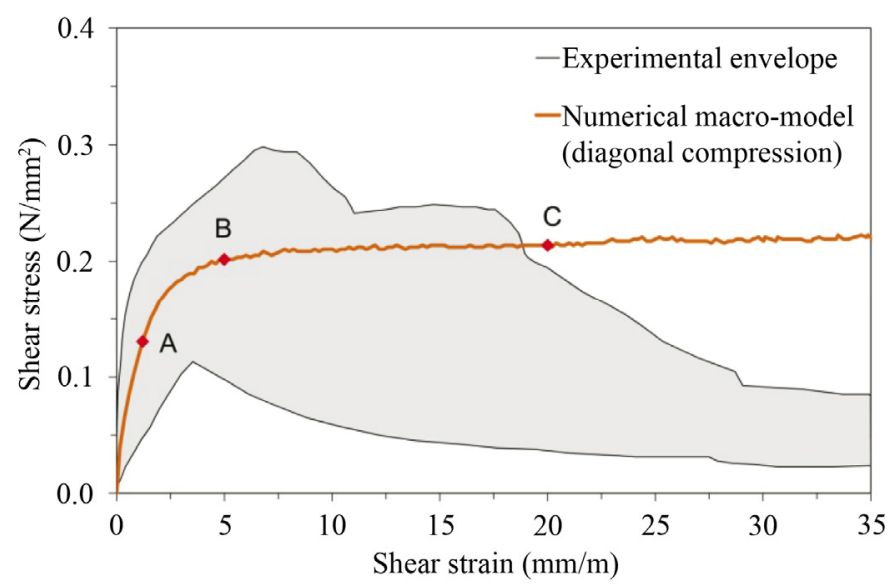

Figure 11: Comparison between experimental and macro-model numerical (Mohr-Coulomb criterion) results for adobe masonry under diagonal compression.

An improvement of the model behaviour for higher values of tangential strain can be attained if more information about the softening behaviour of parameters such as the cohesion coefficient or the friction angle is provided. In Fig. 12, the cracking pattern of the wallet is given, evidencing that the simplified modelling strategy was not able to reproduce the exact cracking pattern observed during the tests, particularly for higher loading steps, requiring for this purpose a more detailed material description and accounting for interface failure mechanisms. 


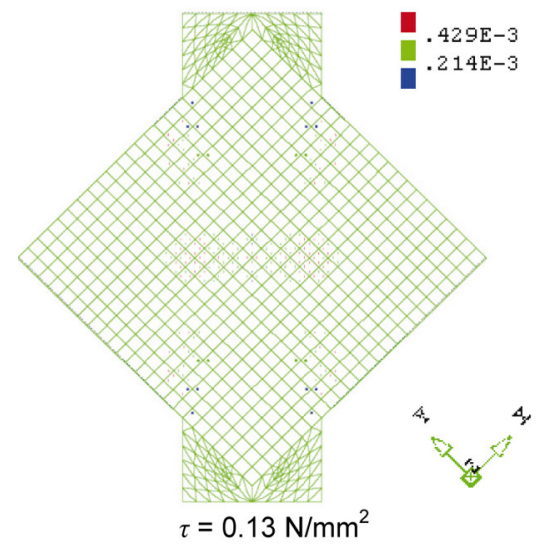

(a)

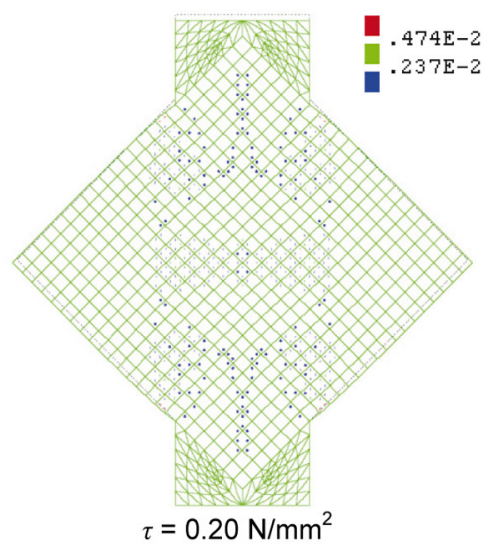

(b)

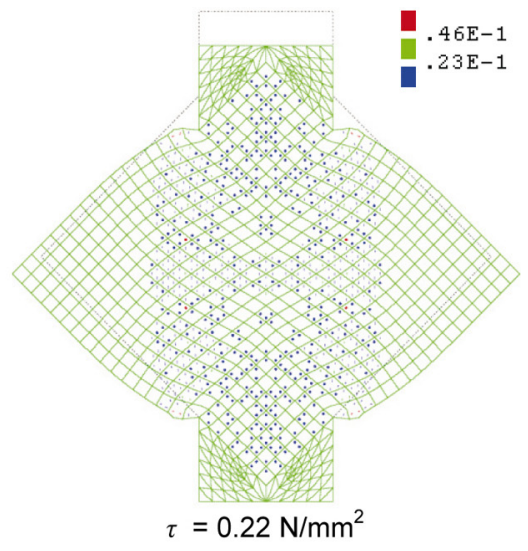

(c)

Figure 12: Cracking progression in the adobe masonry macro-model under diagonal compression at different levels of shear strain: (a) $\gamma_{s}=1.2 \mathrm{~mm} / \mathrm{m}$; (b) $\gamma_{s}=5 \mathrm{~mm} / \mathrm{m}$; (c) $\gamma_{s}=20 \mathrm{~mm} / \mathrm{m}$.

The results obtained from the experimental characterisation of materials carried out in the present study were considered for the values of $f_{c}, c$ and tangent of friction angle $(\tan \varphi)$. For the tensile fracture energy of the interface, data available in the literature suggest values in the range of $0.005-0.2 \mathrm{~N} / \mathrm{mm}$, depending on the unit-mortar combination [34]. The tangent of the dilatancy angle $(\tan \psi)$ was assumed to be zero, as the angle approaches the zero-mark when the normal stress increases and to avoid a non-conservative shear strength prediction [35]. For the values of shear fracture energy and the parameter $\left(C_{s s}\right)$, typical values have been initially considered in the analysis $[30,36]$ and afterwards calibrated on the basis of the experimental results. Several analytical cases were carried out to calibrate and assess the influence of some interface model parameters on the non-linear shear behaviour of the wallet. The parameters examined were the effect of the $\tan \varphi$, the interface compressive strength $\left(f_{c, j o i n t}\right)$, the interface compressive fracture energy $\left(G_{f}^{c}\right)$, and the parameter $C_{s s}$, which allows to take into account the contribution of shear stress to failure. The results of the analysis on the micro-model under uniaxial compression load are reported in Fig. 13.

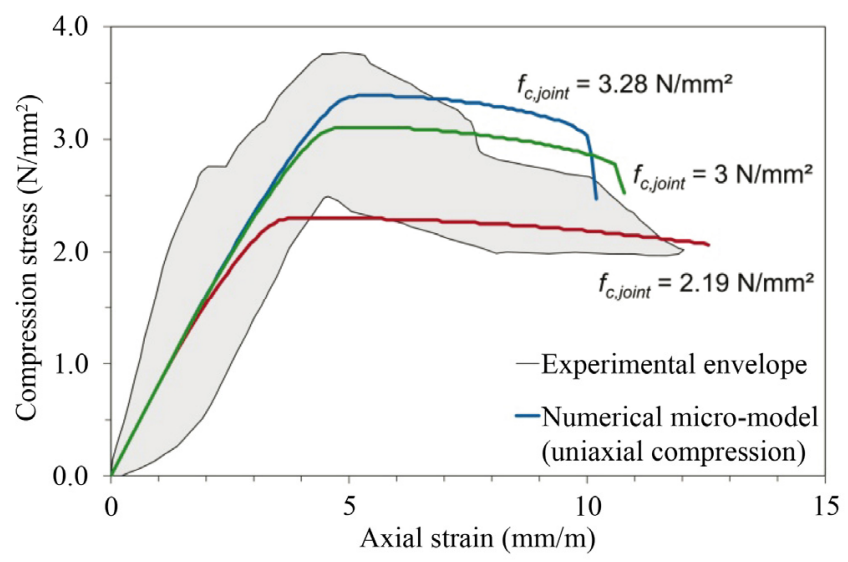

Figure 13: Comparison between experimental and micro-model numerical results for adobe masonry under axial compression.

The analysis was carried out considering a value of $f_{c, j o i n t}$ of $3.28 \mathrm{~N} / \mathrm{mm}^{2}$, equal to the compressive strength of the earthen masonry. This value was considered as an upper limit, and two values of $3.0 \mathrm{~N} / \mathrm{mm}^{2}$ and $2.19 \mathrm{~N} / \mathrm{mm}^{2}$ (Table 6) took into account the high variability of the mechanical properties of the joints mortar with moisture content and curing time, and for 
possible micro-cracking phenomena occurring in the masonry joints during curing and handling operations of the wallets prior to testing. The $\sigma-\varepsilon$ curves correspond to different values of compressive strength of the joints, as indicated in Table 6 . They show the significant dependence of the non-linear behaviour of the micro-model on the characteristics of the joints, in the case of uniaxial compressive loading. In fact, in this case, all the sources of nonlinearity were concentrated in the unit-joint interfaces' behaviour for which it was only possible to set a parabolic softening law for the compression side. Such a law is not able to perfectly follow the experimental post-peak behaviour, especially in the case of simple uniaxial compressive loading. On the contrary, this drawback was not found in the case of the macromodel, where it was possible to set a generic multilinear law for compression. In Fig. 14, the numerical non-linear $\tau-\gamma$ curves obtained for two values of the interface compressive strength are illustrated and compared with the experimental results.

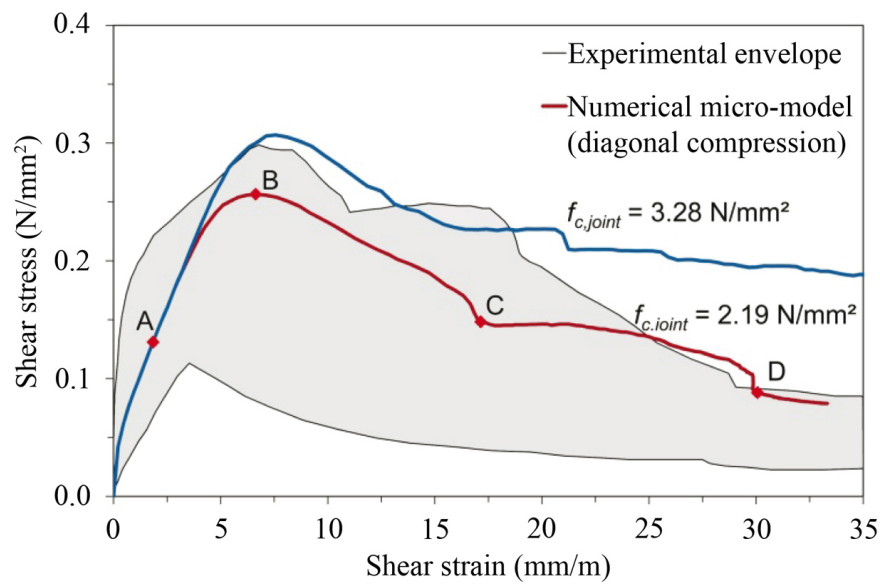

Figure 14: Comparison between experimental and micro-model numerical results for adobe masonry under diagonal compression.

The value of $f_{c, j o i n t}=3.28 \mathrm{~N} / \mathrm{mm}^{2}$ resulted in a shear curve, which approximated the experimental curves corresponding to higher shear strength, while the value of $f_{c, j o i n t}=2.19 \mathrm{~N} / \mathrm{mm}^{2}$ led to a curve in good agreement with the experimental results. With respect to the latter case, as indicated in the graph, four analysis steps have been considered: (a) $0.5 \tau_{\max }=0.13 \mathrm{~N} / \mathrm{mm}^{2}$; $\gamma_{s}=1.8 \mathrm{~mm} / \mathrm{m}$; (b) $\tau_{\max }=0.26 \mathrm{~N} / \mathrm{mm}^{2} ; \gamma_{s}=6.6 \mathrm{~mm} / \mathrm{m}$; (c) $\tau=0.15 \mathrm{~N} / \mathrm{mm}^{2} ; \gamma_{s}=17 \mathrm{~mm} / \mathrm{m}$; (d) $\tau=0.095 \mathrm{~N} / \mathrm{mm}^{2} ; \gamma_{s}=3.0 \%$. For the considered steps, Fig. 15 shows the minimum (compressive) principal stress distribution. The evolution of the compressed strut which forms diagonally in the wallet during the loading process is shown as well.

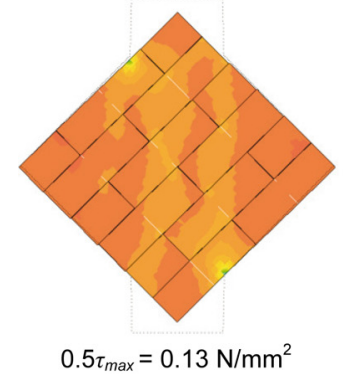

(a)

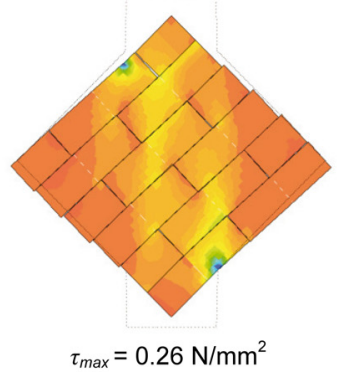

(b)

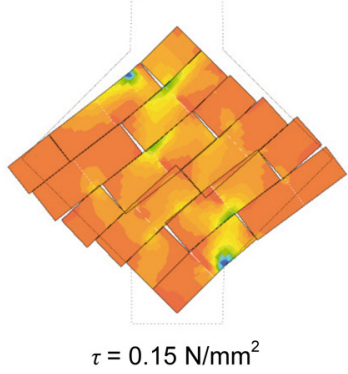

(c)

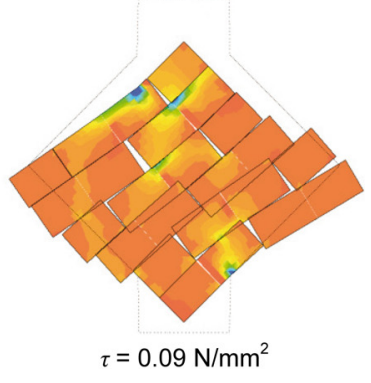

(d)

Figure 15: Minimum principal stresses $\left(\mathrm{N} / \mathrm{mm}^{2}\right)$ of the micro-model of the adobe masonry under diagonal compression at different levels of shear strain: (a) $\gamma_{s}=2 \mathrm{~mm} / \mathrm{m}$; (b) $\gamma_{s}=7 \mathrm{~mm} / \mathrm{m}$; (c) $\gamma_{s}=17 \mathrm{~mm} / \mathrm{m}$; (d) $\gamma_{s}=30$ $\mathrm{mm} / \mathrm{m}$. Yellow and white colours indicate cracking. 


\subsection{Rammed earth}

\subsubsection{Constitutive laws}

The material behaviour of rammed earth and cob wallets was simulated by using the TSRCM. The TSRCM consists on a model of distributed and rotating cracks based on total strains. In this model, the crack direction rotates with the principal strain axes [37, 38, 39], and it embodies several possible non-linear stress-strain relationships for the compressive and tensile behaviours. TSRCM is often used in the numerical modelling of historical constructions, where the compressive behaviour of masonry is in general represented with a parabolic relationship [40, 41]. However, this relationship was shown to be excessively stiff and incapable of representing the large non-linear behaviour of earthen materials [8, 42].

These relationships were initially assumed to be parabolic in compression (Fig. 16a) and exponential in tension (Fig. 16b). However, it should be noted that the parabolic relationship in compression was later changed to a multi-linear relationship, as discussed in the next section. The crack band width $(h)$ of the elements was assumed to be dependent on the area of the element $(A)$, according to Eq. (3). The unloading and reloading of the TSRCM is simulated by a secant approach, see [21, 43] for further details. The initial values assumed for the parameters required by the TSRCM are reported in Table 8 . The average results obtained from the uniaxial compression tests were used to define the initial values of $f_{c}, E$ and $v$. The initial values of the remaining parameters were assumed on the base of recommended values for historical masonry. The compressive fracture energy $\left(G_{c}\right)$ was estimated as $1.6 f_{c}$, the tensile strength $\left(f_{t}\right)$ as $0.1 f_{c}$, the mode-I tensile fracture energy $\left(G_{f}^{I}\right)$ as $0.029 f_{t}$. The micro-model interface elements were modelled using the non-linear Coulomb friction model (Fig. 16c).

$$
h=\sqrt{A}
$$

\begin{tabular}{lllllll}
\hline TSRCM & \multicolumn{6}{l}{} \\
\hline Material & $\begin{array}{l}E \\
\left(\mathrm{~N} / \mathrm{mm}^{2}\right)\end{array}$ & $\begin{array}{l}v \\
(-)\end{array}$ & $\begin{array}{l}f_{c} \\
\left(\mathrm{~N} / \mathrm{mm}^{2}\right)\end{array}$ & $\begin{array}{l}G_{c} \\
(\mathrm{~N} / \mathrm{mm})\end{array}$ & $\begin{array}{l}f_{t} \\
\left(\mathrm{~N} / \mathrm{mm}^{2}\right)\end{array}$ & $\begin{array}{l}G^{I} \\
(\mathrm{~N} / \mathrm{mm})\end{array}$ \\
\hline Rammed earth & 4207 & 0.27 & 3.7 & 5.98 & 0.37 & 0.011 \\
\hline Coulomb friction model & & & & & \\
\hline Material & $k_{n}$ & $k_{s}$ & $c$ & $\tan \varphi$ & $\tan \psi$ & $f_{t}^{t}$ \\
& $\left(\mathrm{~N} / \mathrm{mm}^{3}\right)$ & $\left(\mathrm{N} / \mathrm{mm}^{3}\right)$ & $\left(\mathrm{N} / \mathrm{mm}^{2}\right)$ & $(-)$ & $(-)$ & $(\mathrm{N} / \mathrm{mm})$ \\
\hline Interface & $4.21 \cdot 10^{5}$ & $1.66 \cdot 10^{5}$ & 0.56 & 0.75 & 0 & 0.25 \\
\hline
\end{tabular}

Table 8: Initial values of parameters assumed for the numerical modelling of rammed earth.

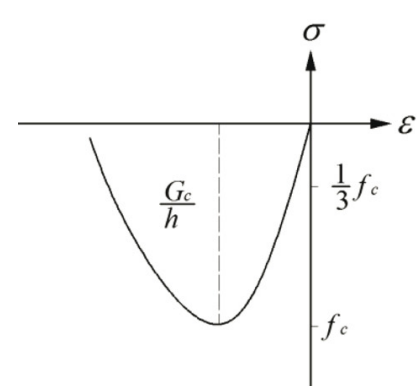

(a)

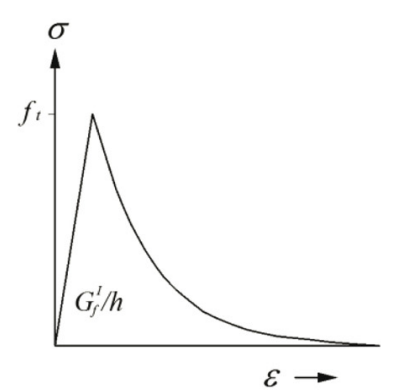

(b)

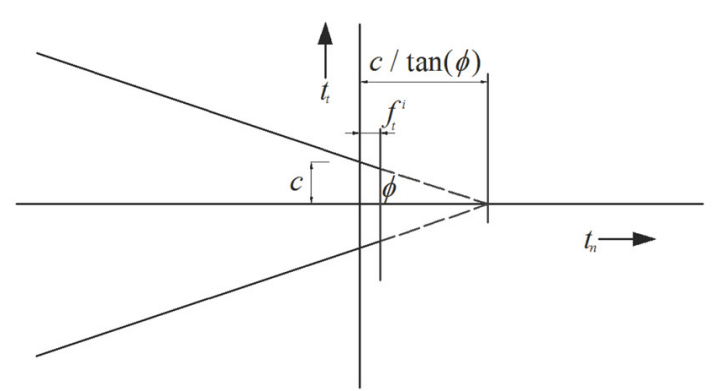

(c)

Figure 16: Stress-strain relationships adopted in the TSRCM for rammed earth modelling: (a) compression; (b) tension. Coulomb friction model used in the modelling of the interfaces between rammed earth layers: (c). 
The parameters required by this model were neither determined experimentally nor available in the literature for the case of rammed earth. This means that these parameters had to be carefully estimated with basis on recommended values for the micro-modelling of historical masonry. The initial values of the interface normal stiffness $\left(k_{n}\right)$ and of the shear stiffness $\left(k_{t}\right)$ were firstly assumed to be very high, to avoid concentrating the elastic deformations in the interface elements. Therefore, $k_{n}$ was assumed as $100 E$ and $k_{s}$ was estimated using Eq. (4). The cohesion $(c)$ was estimated as a function of the tensile strength estimated for the rammed earth, namely as $1.5 f_{t}$. The friction angle $(\phi)$ was assumed to be $37^{\circ}$ and the dilatancy angle $(\psi)$ as zero. The tensile strength of the interfaces $\left(f_{t}^{i}\right)$ was defined as $2 / 3 f_{t}$, while taking into account that the maximum value mathematically allowed by the model is $c / \tan \phi$. Finally, the tensile behaviour of the interfaces was assumed as brittle.

$$
k_{s}=\frac{k_{n}}{2(1+v)}
$$

\subsubsection{Calibration of the models and results}

The calibration of the models consisted in an iterative process where the numerical response was compared against the experimental envelopes. Firstly, the values adopted for the stiffness of the interface elements were assessed by comparing the macro- and micro-model tests. This process was carried out by considering the initial values of the parameters, and by increasing and decreasing both in about one order magnitude. Fig. 17a presents the uniaxial compressive stress-axial strain curves of the models.

The values of the stiffness adopted for the interfaces of the reference micro-model (Micro_ref) seem to be compatible with the deformability of the reference macro-model (Macro_ref), since the curves were almost coincident. Adopting a stiffness one order of magnitude higher than the reference value (Micro_10k) seems to bring the curves even closer. However, it was observed that adopting excessively high values of interface stiffness caused convergence problems in the models of the diagonal compression tests. On the other hand, a value of stiffness one order of magnitude lower than the reference value (Micro_0.1k) deviates considerably the curve from that of the macro-model. This means that in this case the deformation of the model concentrated mainly in the interfaces. Therefore, it was decided to keep the initial values of the stiffness. Fig. 17a also shows that the models seem to be excessively stiff for simulating the compressive behaviour of rammed earth. In fact, the numerical curves present a good fitting with the experimental envelope up to about $1 / 3$ of the maximum compressive stress $\left(\sim 1.2 \mathrm{~N} / \mathrm{mm}^{2}\right)$, where the experimental behaviour is apparently linear. Beyond this point, the adopted numerical models are not able to follow the early non-linear behaviour depicted by the experimental envelope. However, the parabolic relationship available in TNO DIANA software [21] does not allow adjusting its pre-peak behaviour, in terms of deformability, to overcome this limitation. Therefore, a multi-linear relationship was adopted, instead. This relationship was calibrated considering the average curve of the uniaxial compression tests, resulting in the curve depicted in Fig. 17b. The second point of the multi-linear relationship was defined for $0.3 f_{c}$ and taking into account the experimental $E$. 


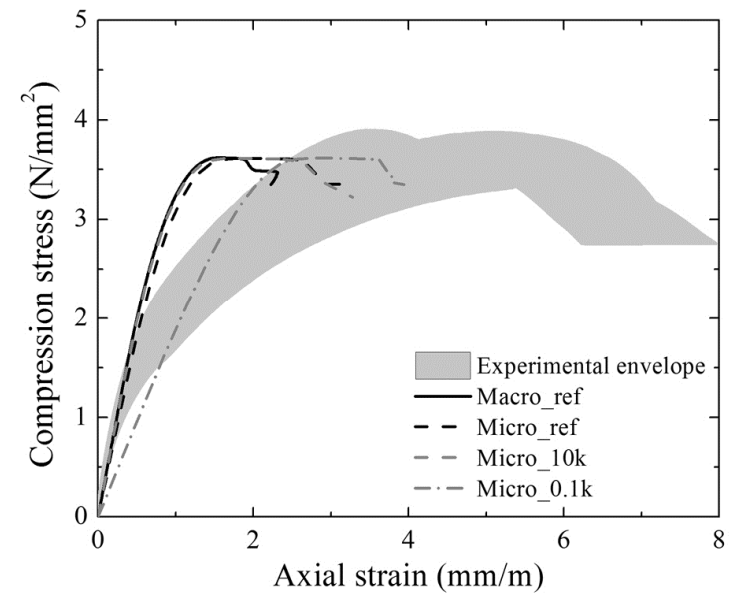

(a)

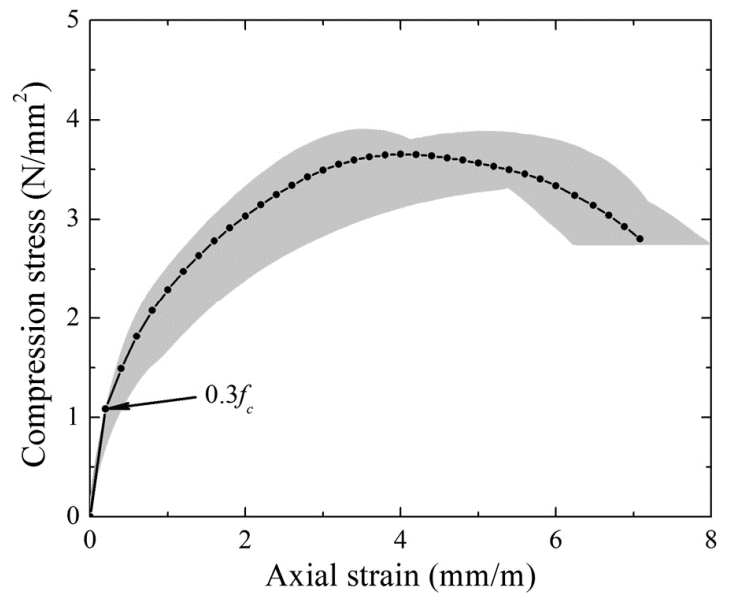

(b)

Figure 17: Stress-strain curves of the rammed earth models under compression: (a) Influence of the stiffness of the interface elements on the deformability; (b) Multi-linear relationship substituting the parabolic relationship in compression.

Fig. 18a presents the shear stress-shear strain curves of the macro- and micro-model of the diagonal compression tests using the reference values of the parameters and the multi-linear relationship previously calibrated under uniaxial compression. Both models present similar curves and a behaviour much more brittle than that of the experimental curves. This means that the calibration of the models requires adjusting $G^{I} f$, which is the main parameter controlling the brittleness. Fig. $18 \mathrm{~b}$ depicts the curves of the calibrated models, which resulted from an increase of the initial value of this parameter in about 10 times. This important increase is justified by the fact that rammed earth behaves as a monolithic material more than masonry does. Furthermore, the rammed earth features a broad particle size distribution (PSD), which includes particles with large dimensions. This factor has great contribution for the interlocking at the crack surfaces by promoting its roughness. This aspect enhances the fracture energy of rammed earth relative to historical masonry, where cracking occurs mostly at less rough surfaces, namely the interfaces between mortar and masonry units. The curve of the macromodel is characterized by an early peak shear stress, followed by a small shear hardening until the maximum shear stress is achieved. On the other hand, the curve of the micro-model does not exhibit this early peak shear stress.

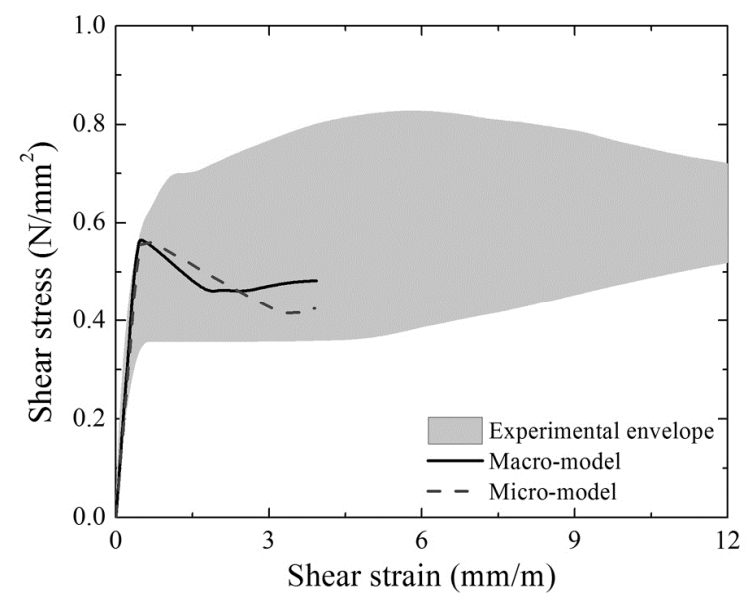

(a)

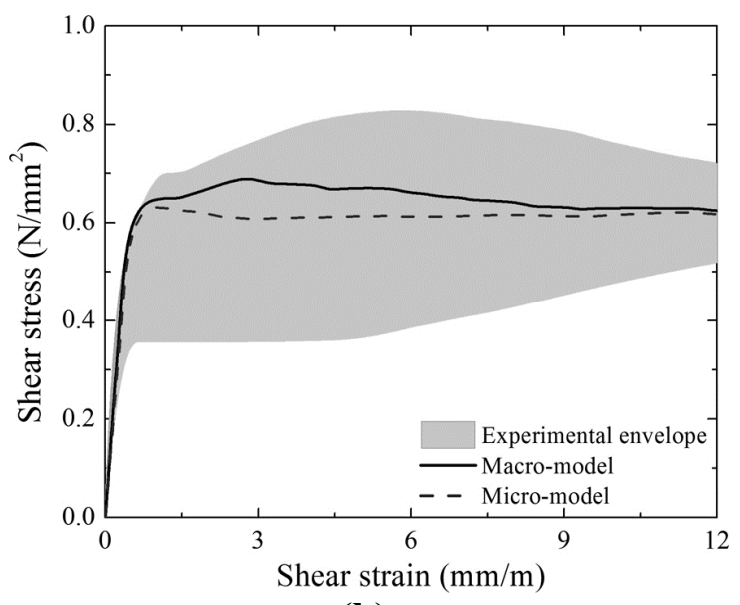

(b)

Figure 18: Behaviour of the macro- and micro-model of the rammed earth under diagonal compression: (a) using the initial parameters; (b) after calibration. 
The model achieves first the maximum shear stress, followed by a drop in stress with a subtle shear softening. Possibly, this drop in stress is related to the failure of interface elements, which is then compensated with stress redistribution. However, the development of the macro-model curve is closer to those obtained from experimental tests. The macro-model presents higher maximum shear stress than the micro-model, whose values are $0.69 \mathrm{~N} / \mathrm{mm}^{2}$ and $0.63 \mathrm{~N} / \mathrm{mm}^{2}$, respectively. Both values correspond to a minor underestimation of the average shear strength obtained from the experimental tests $\left(0.70 \mathrm{~N} / \mathrm{mm}^{2}\right)$. In general, it is shown that both curves fit within the experimental envelope, meaning that the use of the TSRCM might provide good results when modelling full rammed earth structures.

The failure modes of both models were also analysed. Fig. 19 and Fig. 20 present the maximum principal strains obtained for an imposed vertical displacement of $1.00 \mathrm{~mm}$. The damage of both models is shown to concentrate in the middle due to the development of tensile stresses, and at the supports due to stress concentration. This corresponds to the evolution of the system of cracks observed in the experiments. In the macro-model, damage is also observed to occur at the four borders of the model, which indicates that these regions are vulnerable to the occurrence of delamination failure. The micro-model confirms the occurrence of this failure mode, since it is possible to observe the failure of interface elements at two of the borders, as also observed in the experimental tests.
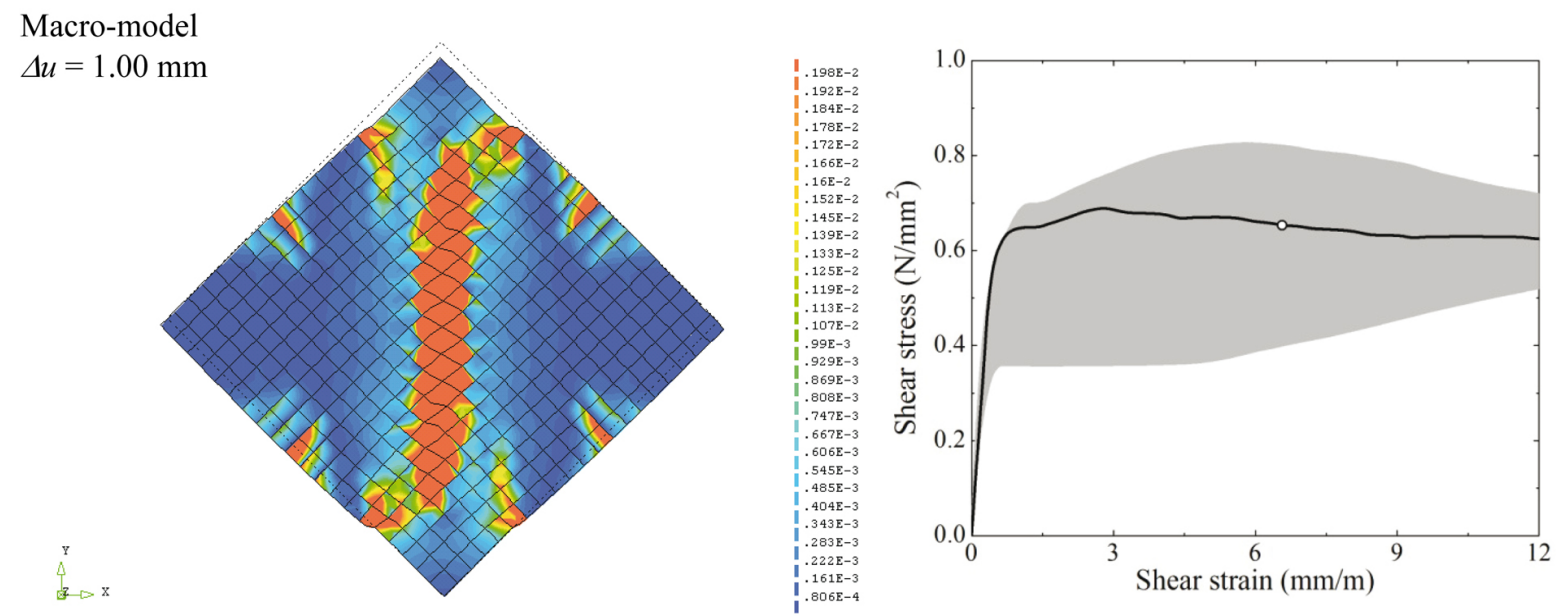

Figure 19: Maximum principal tensile strains for an imposed vertical displacement $(\Delta \mathrm{u})$ of $1 \mathrm{~mm}$ : rammed earth diagonal compression macro-model.

Micro-model $\Delta u=1.00 \mathrm{~mm}$

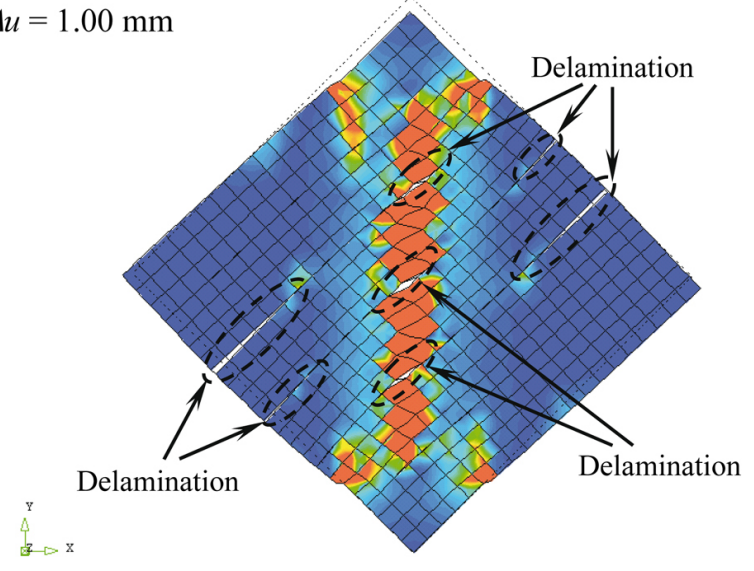

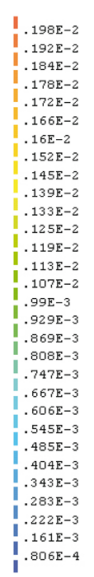

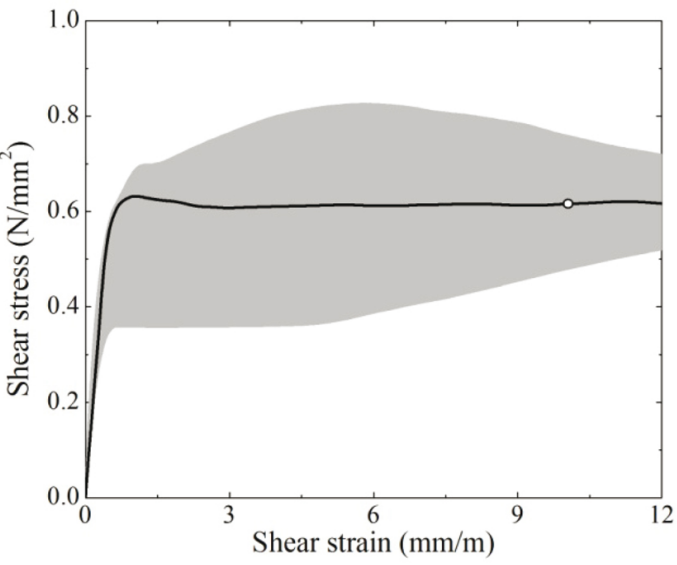

Figure 20: Maximum principal tensile strains for an imposed vertical displacement $(\Delta \mathrm{u})$ of $1 \mathrm{~mm}$ : rammed earth diagonal compression micro-model. 
Furthermore, this model also shows that delamination can occur in the central region, where the diagonal system of cracks is developed. In general, both models are capable of detecting potential zones of failure by delamination. However, the macro-model does not allow controlling this failure mode, neither allows differentiating it from the failure of the rammed earth material.

\subsection{Cob}

\subsubsection{Constitutive laws}

A multi-linear approach for the compressive behaviour, proposed by Miccoli et al. [8], is adopted here for the modelling of cob, which is presented in Fig. 21. This relationship includes a linear branch up to $0.3 f_{c}$, proportional to the average $E$. The compression tests did not allow defining the post-peak behaviour in its full extension, although it was observed to be very resilient. Thus, a negative stiffness equal to $2.0 \%$ of the average $E$ was considered. As shown in Fig 17b, the relationship in tension was presumed to be exponential.

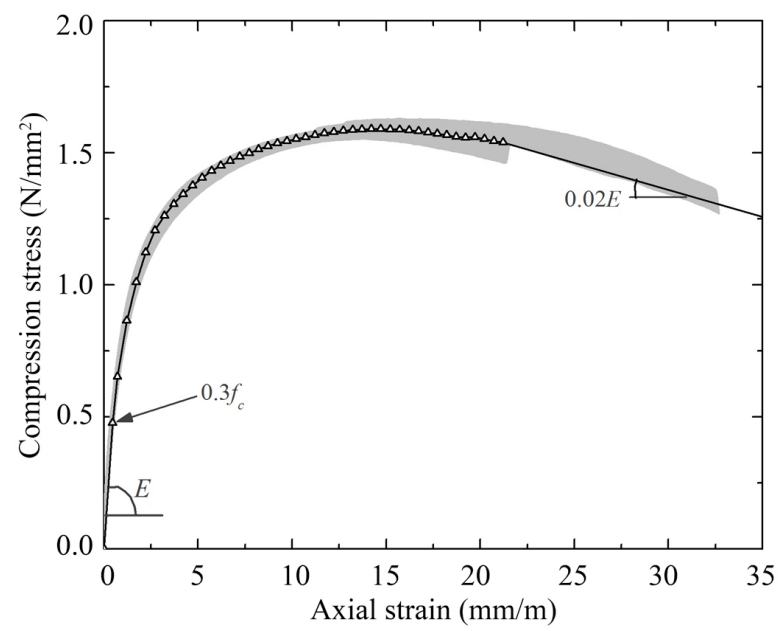

Figure 21: Stress-strain relationship in axial compression adopted in the TSRM for modelling cob.

As for rammed earth, the crack band width (h) was assumed to depend on the element area (Eq. 3). The unloading and reloading of the TSRCM is simulated by a secant approach [21, 43]. The initial values assumed for the parameters required by the TSRCM were based on average values obtained from the compression tests, namely $f_{c}, E$ and $v$. Since the estimation of tensile strength provided by the pull-off tests is expected to lead to an overestimation of this parameter, it was decided to estimate the parameters required by the exponential relationship with basis on suggested values for historical masonry. The values of $f_{t}$ and $G_{f}^{I}$ were estimated as $0.1 f_{c}$ and $0.029 f_{t}$, respectively. Table 9 summarises the initial values of the parameters adopted in the model.

\begin{tabular}{lllll}
\hline$f_{c}$ & $E$ & $v$ & $f_{t}$ & $G_{f}^{I}$ \\
$\left(\mathrm{~N} / \mathrm{mm}^{2}\right)$ & $\left(\mathrm{N} / \mathrm{mm}^{2}\right)$ & $(-)$ & $\left(\mathrm{N} / \mathrm{mm}^{2}\right)$ & $(\mathrm{N} / \mathrm{mm})$ \\
\hline 1.59 & 1021 & 0.14 & 0.159 & 0.0046 \\
\hline
\end{tabular}

Table 9: Initial values of the parameters assumed for the macro-model of cob. 


\subsubsection{Calibration of the models and results}

The calibration of the model was carried out through an iterative process of comparison between the numerical response and the experimental envelope. This process was carried out by fixing the initial values of the parameters obtained directly from tests, namely $f_{c}, E$ and $v$, while $f_{t}$ and $G_{f}{ }$ were adjusted. Fig. 22a presents the shear stress-shear strain curve of the model considering the initial values of the input parameters and those after calibration. The initial values adopted seem not to promote a good match with the experimental results. In this case, the $f_{s}$ of the model achieves a value of about $0.35 \mathrm{~N} / \mathrm{mm}^{2}$, which corresponds to $70 \%$ of the average value obtained from the experimental tests. The respective strain $\gamma_{s}$ achieved a value of $12.7 \mathrm{~mm} / \mathrm{m}$, which corresponds to a deviation of $51 \%$ in relation to the experimental average. Furthermore, the numerical response seems to lead to a rather brittle failure when compared with the experimental behaviour, where the shear strain boosts after achieving a peak shear stress. This means that the relationships typically used for historical masonry for estimating $f_{t}$ and $G_{f}^{I}$ do not seem to be adequate in the case of cob.

The calibration of the model was achieved after increasing the initial values of $f_{t}$ and $G_{f} I_{f}$ in about 1.3 and 25 times, respectively (see Table 10).

\begin{tabular}{lllll}
\hline$f_{c}$ & $E$ & $v$ & $f_{t}$ & $G_{f}^{I_{f}}$ \\
$\left(\mathrm{~N} / \mathrm{mm}^{2}\right)$ & $\left(\mathrm{N} / \mathrm{mm}^{2}\right)$ & $(-)$ & $\left(\mathrm{N} / \mathrm{mm}^{2}\right)$ & $(\mathrm{N} / \mathrm{mm})$ \\
\hline 1.59 & 1021 & 0.14 & 0.207 & 0.1155 \\
\hline
\end{tabular}

Table 10: Calibrated values of the parameters assumed for the macro-model of cob.

The fact that cob is a monolithical material (absence of discrete joints) and that presents straw (fibres) in its constitution, justifies an increase in tensile strength with respect to the initial value. The presence of straw also justifies a much larger fracture energy value. For instance, Aymerich et al. [44] reports bending tests on beams made of earth reinforced with wool fibres, where the calculated $G_{f}^{I}$ achieves to values of about $2 \mathrm{~N} / \mathrm{mm}$, which is still higher than the value used in the calibrated model.

On average terms, the calibrated model shows good match with the experimental response. The model achieved a maximum shear stress of about $0.45 \mathrm{~N} / \mathrm{mm}^{2}$, which corresponds to $90 \%$ of the average value obtained from the experimental tests, while the respective shear strain was of about $7.6 \mathrm{~mm} / \mathrm{m}$, corresponding to a deviation of about $10 \%$. The shear modulus found in the calibrated model was of about $363 \mathrm{~N} / \mathrm{mm}^{2}$, corresponding to a deviation of about $18 \%$ in relation to the average of the experimental values. The shear modulus of the calibrated model is controlled by the elastic parameters ( $E$ and $v)$, which were defined with basis on the compression tests. Despite of the deviation found, these parameters still result within the range of variation of the experimental tests for the shear modulus.

The judgement on the agreement between numerical and experimental responses is largely affected by the high scattering observed in the diagonal compression tests. Therefore, it was decided to assess the agreement in terms of normalised shear stress-shear strain curves, see Fig. 22b. Each of the experimental curves was normalised by dividing shear stresses and shear strains by the corresponding $f_{s}$ and $\gamma_{s}$, respectively. The normalised experimental curves show lower scattering than the non-normalized ones, meaning that the development of the former is very similar. With respect to the normalised numerical response, a good agreement is found with the experimental results. This means that the numerical model is fully capable of capturing the development of the pre-peak shear stress-shear strain curves. 


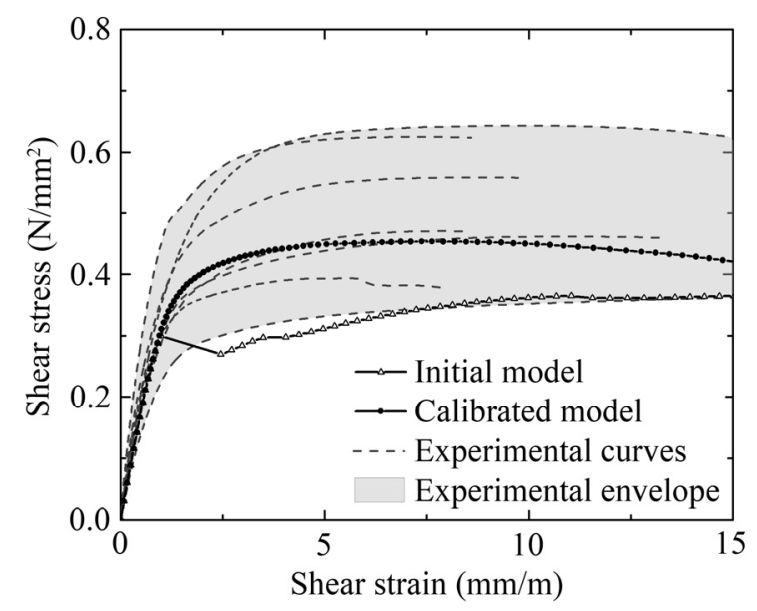

(a)

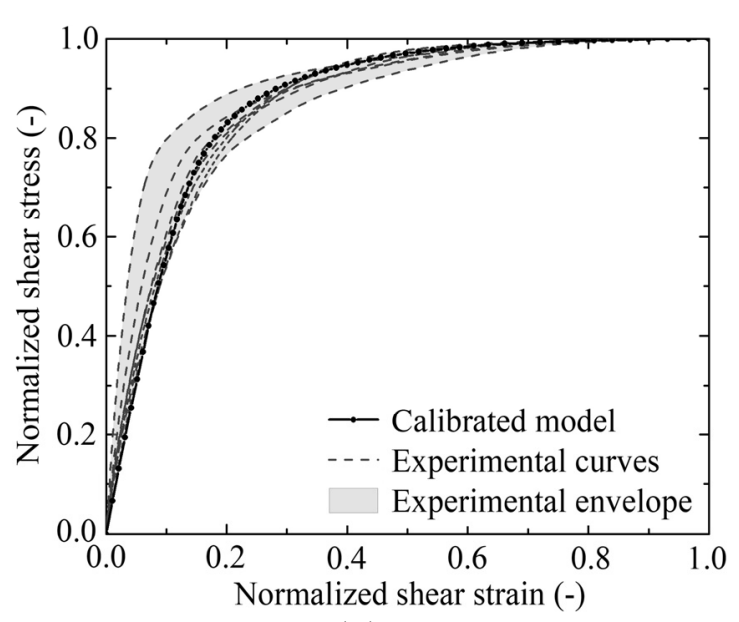

(b)

Figure 22: Comparison of the responses of the numerical model and experimental tests of cob: (a) shear stressshear strain curves; (b) normalised shear stress-shear strain curves.

The simulation of the damage occurring in the experimental tests was also possible, as shown by the numerical maximum principal strains in four critical load levels. These load levels are given in Fig. 23 and were defined as function of $f_{s}$, namely $0.83 f_{s}, 0.92 f_{s}, 0.97 f_{s}$ and $1.0 f_{s}$.

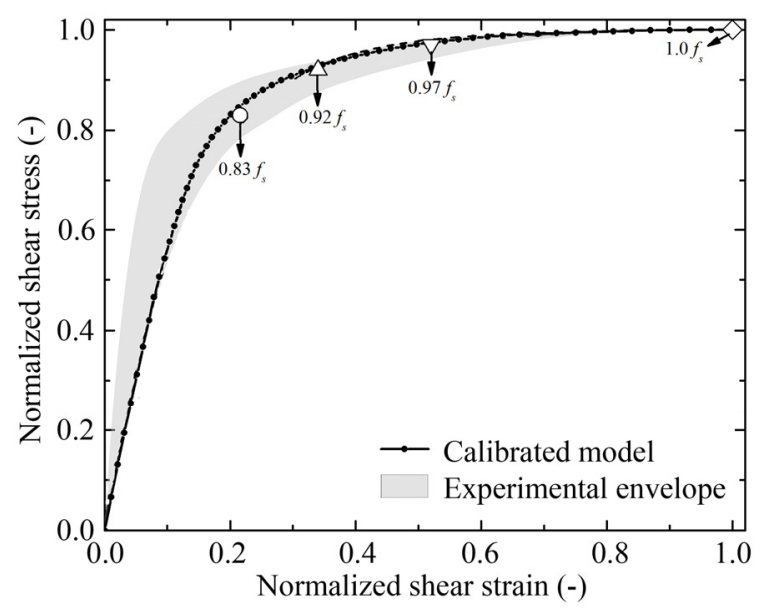

Figure 23: Critical points used to compare the damage in the model and that occurred in the cob wallets.

The maximum principal strains obtained in these critical load levels are compared in Fig. 24. The numerical model replicates well the damage observed in the wallets during their test. In stress level $0.83 f_{s}$, no relevant cracking was detected in the samples, where the numerical model demonstrates also lack of this type of damage. The initiation of cracking damage was observed in the samples to occur just before $0.92 f_{s}$, where the numerical model seems to show the initiation of a middle crack. The numerical model in stress level $0.97 f_{s}$ evidences the development of the middle crack towards the supports and the development of damage in terms of crack widening. Finally, stress level 1.0 $f_{s}$ shows the full development of the crack in both the samples and the model. However, the numerical model is incapable of capturing the diagonal orientation of the crack observed in the experimental tests, which is most probably a consequence of lack of symmetry in the samples (e.g. imperfections) and testing setup. 


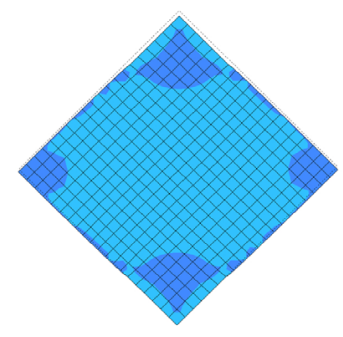

(a)

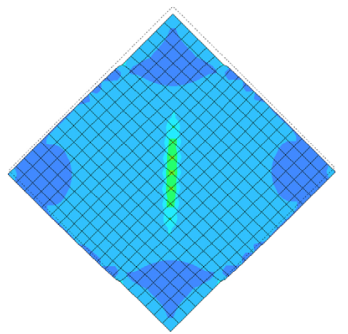

(b)

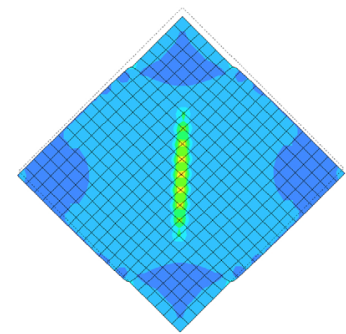

(c)

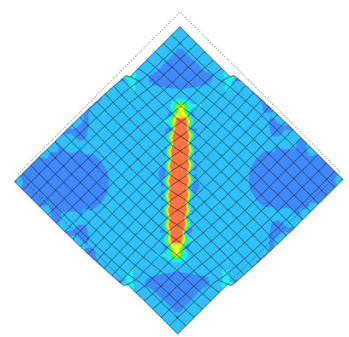

(d)

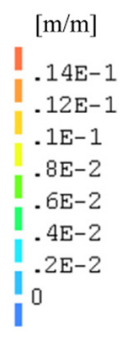

Figure 24: Maximum principal strains obtained in the numerical model of cob for the critical points: (a) $0.83 f_{s}$; (b) $0.92 f_{s}$; (c) $0.97 f_{s}$; (d) $1.0 f_{s}$.

\section{CONCLUSIONS}

An analysis of the mechanical properties of three traditional earthen construction materials is presented based on compressive and shear test results. Uniaxial compressive and diagonal compression tests on wallets were carried out to determine basic mechanical parameters and in particular the post-peak strain behaviour.

The experimental results were used to calibrate the behaviour of adobe masonry, rammed earth and cob wallets by means of non-linear finite element method based on the macro- and micro-modelling approaches. Appropriate constitutive behaviour was considered and the chosen geometries were in respect with the restraint conditions observed in laboratory testing. For adobe masonry, a finite element macro-model calibrated on the basis of the experimental data was firstly developed, which resulted in a useful prediction of the strength of adobe masonry elements. The numerical stress-strain curve provided by the macro-model of the wallet tested under uniaxial compression was in good correspondence with the experimental ones, also considering the post-elastic behaviour. A simplified approach based on macro-modelling and the homogeneous equivalent material calibrated in this phase can be adopted for the study of larger structural systems or entire buildings, being characterised by satisfactory accuracy and lower computational cost. Although the global stress-strain behaviour was found to be satisfactory, the appropriateness of such non-linear isotropic continuum models for adobe masonry is not fully confirmed considering the observation of the crack pattern.

A detailed analysis of the mechanical behaviour of the tested adobe wallets was carried out following a micro-modelling approach. The model allowed to take into account all the possible failure mechanisms occurring in the masonry elements and was found to be particularly suitable for the description of masonry shear behaviour. The analysis of principal stresses distribution during the non-linear analysis provided information about the actual mechanisms of load transfer between blocks and mortar joints. The micro-models were able to reproduce the correct non-linear behaviour of earthen masonry and represent a suitable tool for the prediction of the masonry collapse mechanisms, as shown by the comparison with the failure modes observed during the tests.

A list of recommended values for the parameters in the models is presented in Table 11, based on the results from experimental testing and with basis on the numerical analysis performed in this paper.

The non-linear behaviour of rammed earth was modelled using the TSRCM to simulate the behaviour of the rammed earth material, while the Mohr-Coulomb failure criterion was used to model the interfaces between layers. The compression behaviour of the rammed earth was simulated using a multi-linear relationship. This relationship was built considering the average stress-strain curve of the compression tests. This assumption was necessary to obtain a good agreement with the experimental results of the compression tests. 


\begin{tabular}{|c|c|c|c|c|c|c|}
\hline \multicolumn{7}{|c|}{ Equivalent homogeneous material (macro-modelling) } \\
\hline \multicolumn{5}{|c|}{$\begin{array}{l}\text { Compressive behaviour } \\
\text { (multi-linear constitutive law*) }\end{array}$} & \multicolumn{2}{|c|}{$\begin{array}{l}\text { Tensile behaviour } \\
\text { (brittle constitutive law) }\end{array}$} \\
\hline $\begin{array}{l}E \\
\left(\mathrm{~N} / \mathrm{mm}^{2}\right)\end{array}$ & $\begin{array}{l}v \\
(-)\end{array}$ & $\begin{array}{l}f_{c} \\
\left(\mathrm{~N} / \mathrm{mm}^{2}\right)\end{array}$ & $\begin{array}{l}\varepsilon m a x \\
(\%)\end{array}$ & $G_{f}^{c}(\mathrm{~N} / \mathrm{mm})$ & $\begin{array}{l}E \\
\left(\mathrm{~N} / \mathrm{mm}^{2}\right)\end{array}$ & $\begin{array}{ll}v & f_{t} \\
(-) & \left(\mathrm{N} / \mathrm{mm}^{2}\right)\end{array}$ \\
\hline$*$ & $*$ & * & $\begin{array}{l}(2.8-3.2) \\
f_{c} / E\end{array}$ & $\begin{array}{l}\text { Multi-linear } \\
\text { relations.* }\end{array}$ & $*$ & $* \quad(0.09-0.11) f_{c}$ \\
\hline \multicolumn{5}{|c|}{ Shear behaviour (constant shear retention) } & \multicolumn{2}{|c|}{ Mohr-Coulomb criterion } \\
\hline $\begin{array}{l}\beta \\
\beta \\
(-)\end{array}$ & & & & & $\begin{array}{l}c \\
\left(\mathrm{~N} / \mathrm{mm}^{2}\right)\end{array}$ & $\begin{array}{l}\tan \phi \\
(-)\end{array}$ \\
\hline 0.2 & & & & & $(0.05-0.10) f_{t}$ & $0.575-1.15$ \\
\hline \multicolumn{7}{|c|}{ Micro-modelling } \\
\hline \multicolumn{5}{|l|}{ Blocks } & \multicolumn{2}{|l|}{ Block cracks } \\
\hline $\begin{array}{l}E \\
\left(\mathrm{~N} / \mathrm{mm}^{2}\right)\end{array}$ & $\begin{array}{l}v \\
(-)\end{array}$ & & & & $\begin{array}{l}f_{t, \text { crack }} \\
\left(\mathrm{N} / \mathrm{mm}^{2}\right)\end{array}$ & $\begin{array}{l}G_{\text {f,crack }}^{I} \\
(\mathrm{~N} / \mathrm{mm})\end{array}$ \\
\hline$*$ & $*$ & & & & $*$ & $(0.1-0.5) f_{t, \text { crack }}$ \\
\hline \multicolumn{7}{|c|}{ Joint interface } \\
\hline $\begin{array}{l}f_{t, \text { joint }} \\
\left(\mathrm{N} / \mathrm{mm}^{2}\right)\end{array}$ & $\begin{array}{l}G_{f}^{I_{f}} \\
(\mathrm{~N} / \mathrm{mm})\end{array}$ & $\begin{array}{l}f_{c, j o i n t} \\
\left(\mathrm{~N} / \mathrm{mm}^{2}\right)\end{array}$ & $\begin{array}{l}G_{f}^{c} \\
(\mathrm{~N} / \mathrm{mm})\end{array}$ & $\begin{array}{l}c \\
\left(\mathrm{~N} / \mathrm{mm}^{2}\right)\end{array}$ & $\begin{array}{l}\tan \phi \\
(-)\end{array}$ & $\begin{array}{l}G_{f}^{I I_{f}} \\
(\mathrm{~N} / \mathrm{mm})\end{array}$ \\
\hline $\begin{array}{l}(0.03- \\
0.10) f_{t}\end{array}$ & $0.5 f_{t, j o i n t}$ & $\begin{array}{l}(0.67- \\
1.00) f_{c}\end{array}$ & $\begin{array}{l}(0.25- \\
0.50) f_{c, \text { joint }}\end{array}$ & $\begin{array}{l}(0.05-0.10) \\
f_{t}\end{array}$ & $0.575-1.15$ & 0.05 \\
\hline
\end{tabular}

Table 11: Recommended values for the numerical analysis of adobe masonry. ${ }^{*}$ From testing.

Furthermore, the important non-linear behaviour of rammed earth seems to deem the compression behaviour of this material as non-compatible with relationships traditionally used for modelling masonry. Regarding the simulation of the diagonal compression tests, the calibrated macro- and micro-models demonstrated good comparison with the experimental envelope of the shear stress-shear strain curves and with the experimental damage pattern. The micromodel allowed capturing the failure by delamination of the interfaces between layers, similar to the one observed in the experimental tests. This revealed to be the main advantage of the micro-model approach, yet the macro-model seemed to provide an equivalent numerical simulation of the shear behaviour. Therefore, the macro-modelling approach here presented is sufficiently accurate to simulate the global shear behaviour of the rammed earth walls tested. This approach requires the definition of adequate stress-strain relationships. The use of the micro-modelling approach, where an additional computational effort is required, is justified when specific collapse mechanisms involving failure of the interfaces between layers are expected. The calibration of the models provided a better insight on the macro- and micromodelling of rammed earth walls with the TSRCM and the Coulomb friction model, namely with respect to the definition of the stress-strain relationships and respective parameters. A list of recommended values for the parameters in the models is presented in Table 12, based on the results from compression tests and with basis on the numerical analysis performed in this paper. 


\begin{tabular}{|c|c|c|c|c|c|c|}
\hline \multicolumn{7}{|l|}{ TSRCM } \\
\hline Material & $\begin{array}{l}E \\
\left(\mathrm{~N} / \mathrm{mm}^{2}\right)\end{array}$ & $\begin{array}{l}v \\
(-)\end{array}$ & $\begin{array}{l}f_{c} \\
\left(\mathrm{~N} / \mathrm{mm}^{2}\right)\end{array}$ & $\begin{array}{l}G_{c} \\
(\mathrm{~N} / \mathrm{mm})\end{array}$ & $\begin{array}{l}f_{t} \\
\left(\mathrm{~N} / \mathrm{mm}^{2}\right)\end{array}$ & $\begin{array}{l}G_{f}^{I} \\
(\mathrm{~N} / \mathrm{mm})\end{array}$ \\
\hline \multicolumn{7}{|c|}{ Rammed earth } \\
\hline & $*$ & $*$ & $\begin{array}{l}\text { Multi-linear } \\
\text { relations.* }\end{array}$ & $\begin{array}{l}\text { Multi-linear } \\
\text { relations.* }\end{array}$ & $\begin{array}{l}(0.08-0.12) \\
f_{c}\end{array}$ & $\begin{array}{l}(0.10-0.50) \\
f_{t}\end{array}$ \\
\hline \multicolumn{7}{|c|}{ Coulomb friction model } \\
\hline Material & $\begin{array}{l}k_{n} \\
\left(\mathrm{~N} / \mathrm{mm}^{3}\right)\end{array}$ & $\begin{array}{l}k_{s} \\
\left(\mathrm{~N} / \mathrm{mm}^{3}\right)\end{array}$ & $\begin{array}{l}c \\
\left(\mathrm{~N} / \mathrm{mm}^{2}\right)\end{array}$ & $\begin{array}{l}\tan \varphi \\
(-)\end{array}$ & $\begin{array}{l}\tan \psi \\
(-)\end{array}$ & $\begin{array}{l}f_{t}^{t_{t}} \\
(\mathrm{~N} / \mathrm{mm})\end{array}$ \\
\hline \multicolumn{7}{|l|}{ Interface } \\
\hline & $100 E$ & $k_{s}=\frac{k_{n}}{2(1+v)}$ & $\begin{array}{l}(1.5-2.0) \\
f_{t}\end{array}$ & $0.58-1.00$ & 0 & $\begin{array}{l}(0.67-1.00) \\
f_{t}\end{array}$ \\
\hline
\end{tabular}

Table 12: Recommended values for the numerical analysis of rammed earth. * From testing.

For numerical modelling of the shear behaviour of cob, the TSRCM was adopted. The calibration of the model allowed to verify that relationships typically used for estimating tensile parameters in historical masonry (namely $f_{t}$ and $G_{f}^{I}$ ) are not adequate for cob. With this respect, the calibration of the model resulted in new relationships, where $f_{t}$ was estimated as $0.13 f_{c}$ and $G_{f}^{I}$ as $0.558 f_{t}$. These relationships are of great numerical interest as testing the behaviour in tension is often a difficult task.

The response of the wallets tested under diagonal compression was found to present great variability. However, the numerical model was found to present good match with the experimental data, on average terms. Furthermore, the numerical model was found to capture well the development of the shear stress-shear strain curves and the development of the damage generated during the tests. Therefore, the modelling approach used seems adequate to provide a reliable simulation of the local and global shear behaviour of cob. A list of recommended values is reported in Table 13.

\begin{tabular}{lllll}
\hline$f_{c}$ & $E$ & $v$ & $f_{t}$ & $G_{f}^{I_{f}}$ \\
$\left(\mathrm{~N} / \mathrm{mm}^{2}\right)$ & $\left(\mathrm{N} / \mathrm{mm}^{2}\right)$ & $(-)$ & $\left(\mathrm{N} / \mathrm{mm}^{2}\right)$ & $(\mathrm{N} / \mathrm{mm})$ \\
\hline$*$ & $*$ & $*$ & $(0.10-0.16) f_{c}$ & $(0.3-0.8) f_{t}$ \\
\hline
\end{tabular}

Table 13: Recommended values for the numerical analysis of cob. * From testing.

\section{ACKNOWLEDGEMENTS}

This study was partially funded by European Commission within the framework of the project NIKER (grant number 244123) dealing with improving immovable Cultural Heritage assets against the risk of earthquakes. The study was also partly financed by FEDER funds through the Competitivity Factors Operational Programme (project POCI-01-0145-FEDER007633) and by national funds through Portuguese Foundation for Science and Technology (project PTDC/ECM-EST/2777/2014 and grant SFRH/BPD/97082/2013). The authors wish to acknowledge Mr. André Gardei and Mr. Jürgen Kuhn for their support in samples preparation and tests setup. 


\section{REFERENCES}

[1] F. Pacheco-Torgal, S. Jalali, Earth construction: lessons from the past for future ecoefficient construction. Constr Build Mater, 29, 512-519, 2012.

[2] A. Fabbri, J.C. Morel, Earthen materials and constructions. Nonconventional and Vernacular Construction Materials: Characterisation, Properties and Applications, 273, 2016.

[3] H. Niroumand, M.F.M Zain, M. Jamil, Various types of earth buildings. ProcediaSocial and Behavioral Sciences, 89, 226-230, 2013.

[4] E. Quagliarini, A. Stazi, E. Pasqualini, E. Fratalochi, Cob construction in Italy: some lessons from the past. Sustainability, 2, 3291-3308, 2010.

[5] L. Miccoli, U. Müller, P. Fontana, Mechanical behaviour of earthen materials: a comparison between earth block masonry, rammed earth and cob. Constr Build Mater, 61, 327-339, 2014.

[6] L. Miccoli, P. Fontana, U. Müller, Charakterisierung von Lehmmauerwerk unter statischer Druck-und Schubbeanspruchung, Mauerwerk Kalender 2013, 629-633, 2013.

[7] Q. Piattoni, E. Quagliarini, S. Lenci, Experimental analysis and modelling of the mechanical behaviour of earthen bricks. Constr Build Mater, 25, 2067-2075, 2011.

[8] L. Miccoli, D.V. Oliveira, R.A. Silva, U. Müller, L. Schueremans, Static behaviour of rammed earth: experimental testing and finite element modelling. Mater Struct, 48, 3443-3456, 2015.

[9] L. Miccoli, A. Garofano, P. Fontana, U. Müller, Experimental testing and finite element modelling of earth block masonry. Eng Struct, 104, 80-94, 2015.

[10] L. Miccoli, P. Fontana, Mechanical characterization and modelling of earth block masonry. Mauerwerk, 16, 279-292, 2012.

[11] A. Caporale, F. Parisi, D. Asprone, R. Luciano, A. Prota, Comparative micromechanical assessment of adobe and clay brick masonry assemblages based on experimental data sets. Comp Struct, 120, 208-220, 2015.

[12] V. Giamundo, V. Sarhosis, G.P. Lignola, Y. Sheng, G. Manfredi, Evaluation of different computational modelling strategies for the analysis of low strength masonry structures. Eng Struct, 73, 160-169, 2014.

[13] P.A. Jaquin, Analysis of historic rammed earth construction. 1, PhD thesis. Durham, United Kingdom: Durham University, 2008.

[14] H. Nowamooz, C. Chazallon, Finite element modelling of a rammed earth wall. Constr Build Mater, 25, 2112-2121, 2011.

[15] Q.B. Bui, S. Hans, J.C. Morel, A.P. Do, First exploratory study on dynamic characteristics of rammed earth buildings. Eng Struct, 33, 3690-3695, 2011.

[16] J. Ortega, G. Vasconcelos, P.B. Lourenço, H. Rodrigues, H. Varum, Seismic behaviour assessment of vernacular isolated buildings. In: Seismic Retrofitting: Learning from Vernacular Architecture, 203-212, 2015.

[17] T.T. Bui, Q.B. Bui, A. Limam, J.C. Morel, Modeling rammed earth wall using discrete element method. Continuum Mech Therm, 28, 523-538, 2016. 
[18] I. Gomes, M. Lopes, J. Brito, Seismic resistance of earth construction in Portugal. Eng Struct, 33, 932-941, 2012.

[19] A. Garofano, F. Ceroni, M. Pecce, Modelling of the in-plane behaviour of masonry walls strengthened with polymeric grids embedded in cementitious mortar layers. Compos Part B Eng, 85, 243-258, 2016.

[20] L. Miccoli, A. Drougkas, U. Müller, In-plane behaviour of rammed earth under cyclic loading: experimental testing and finite element modelling. Eng Struct, 125, 144-152, 2016.

[21] TNO. Displacement method analyser (DIANA) User's Manual. Release 9.6, Netherlands, 2015.

[22] DIN 18946. Earth masonry mortar - terms and definitions, requirements, test methods, 2013.

[23] EN 1052-1. Methods of test for masonry - Part 1: Determination of compressive strength, 1998.

[24] ASTM E 519-10. Standard test method for diagonal tension (shear) in masonry assemblages, 2010.

[25] EN 1052-3. Methods of test for masonry - Part 3: Determination of initial shear strength, 2007.

[26] L. Miccoli, R.A. Silva, D.V. Oliveira, U. Müller, Static behaviour of cob: experimental testing and finite element modelling. Eng Struct, 2017 (in print).

[27] J.G. Rots, J. Blaauwendraad, Crack models for concrete: discrete or smeared? Fixed, multi-directional or rotating? Heron, 34, 1989.

[28] V. Saetta, R. Scotta, R.V. Vitaliani, An orthotropic forth-rank damage model for masonry structures. European congress on computational methods in applied sciences and engineering, 2010.

[29] P.B. Lourenço, G. Vasconcelos, J.P. Gouveia. Vertically perforated clay brick masonry for loadbearing and non-loadbearing masonry walls. Constr Build Mater, 24, 2317-2330, 2010 .

[30] P.B. Lourenço, Computational strategies for masonry structures. PhD thesis. Delft, Netherlands: Delft University of Technology, 1996.

[31] J.G. Rots, Structural masonry: an experimental/numerical basis for practical design rules. Balkema, Rotterdam, The Netherlands, 1997.

[32] P.B. Lourenço, J.G. Rots, Multisurface interface model for analysis of masonry structures. J Eng Mech, 123, 660-688, 1997.

[33] R. Senthivel, P.B. Lourenço. Finite element modelling of deformation characteristics of historical stone masonry shear walls. Eng Struct, 31, 1933-1943, 2009.

[34] R. Van der Pluijm, Material properties of masonry and its components under tension and shear. 6th Canadian Masonry Symposium, Saskatchewan, Canada, June 15-17, 1992.

[35] G.P.A.G. Van Zijl, Modelling masonry shear-compression: role of dilatancy angle. $J$ Eng Mech, 130, 1289-1296, 2004. 
[36] F. da Porto, G. Guidi, E. Garbin, C. Modena, In-plane behavior of clay masonry walls: experimental testing and finite-element modeling. J Struct Eng, 136, 1379-1392, 2010.

[37] J. Figueiras, Ultimate load analysis of anisotropic and reinforced concrete plates and shells. PhD Thesis, University of Wales, UK, 1983.

[38] F. Damjamic, D. Owen, Practical considerations for modeling of post-cracking concrete behavior for finite element analysis of reinforced concrete structures. International Conference on Computer Aided Analysis and Design of Concrete Structures, 1984.

[39] R. Póvoas, Non-linear models of analysis and design. PhD thesis, University of Porto, Portugal, 1991.

[40] N. Mendes, P.B. Lourenço, Sensitivity analysis of the seismic performance of existing masonry buildings. Eng Struct, 80, 137-146, 2014.

[41] A. Carpinteri, S. Invernizzi, G. Lacidogna, In situ damage assessment and nonlinear modelling of a historical masonry tower. Eng Struct, 27, 387-395, 2005.

[42] R.A. Silva, D.V. Oliveira, L. Schueremans, T. Miranda, J. Machado, Modelling of the structural behaviour of rammed earth components. 12th International Conference on Computational Structures Technology, Naples, 2014.

[43] N.M. Mendes, Seismic assessment of ancient masonry buildings: shaking table tests and numerical analysis. PhD thesis, University of Minho, Guimarães, Portugal, 2012.

[44] F. Aymerich, L. Fenu, P. Meloni, Effect of reinforcing wool fibres on fracture and energy absorption properties of an earthen material. Constr Build Mater, 27, 66-72, 2012. 